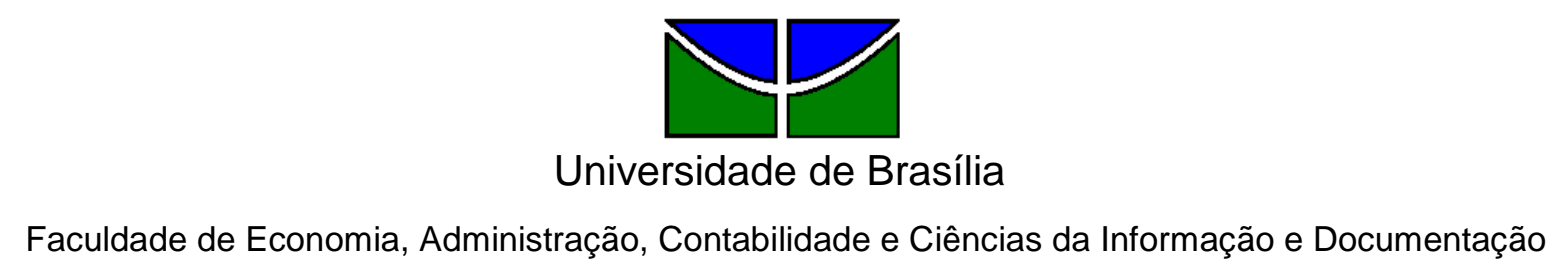

CAMILA DE MEDEIROS ESCOBAR

\title{
PROCESSOS DE APRENDIZAGEM EM GRUPOS DE PESQUISA DA UNIVERSIDADE DE BRASÍLIA
}

Brasília - DF

Dezembro / 2009 
Universidade de Brasília

Faculdade de Economia, Administração, Contabilidade e Ciências da Informação e Documentação

\section{PROCESSOS DE APRENDIZAGEM EM GRUPOS DE PESQUISA DA UNIVERSIDADE DE BRASÍLIA}

Trabalho de Conclusão de Curso apresentado ao Departamento de Administração como requisito parcial à obtenção do título de Bacharel em Administração.

Professora Orientadora: Dra. Catarina Cecília Odelius

Brasília - DF

Dezembro / 2009 
Escobar, Camila de Medeiros.

Processos de Aprendizagem em Grupos de Pesquisa da Universidade de Brasília / Camila de Medeiros Escobar. - Brasília, 2009.

69 f. : il.

Monografia (bacharelado) - Universidade de Brasília, Departamento de Administração, 2009.

Orientador: Prof. ${ }^{\underline{a}}$ Dr. ${ }^{\text {a }}$ Catarina Cecília Odelius, Departamento de Administração.

1. Aprendizagem em Organizações. 2. Processos de Aprendizagem. 3. Grupos de Pesquisa. I. Título. 


\title{
PROCESSOS DE APRENDIZAGEM EM GRUPOS DE PESQUISA DA UNIVERSIDADE DE BRASÍLIA
}

A Comissão Examinadora, abaixo identificada, aprova o Trabalho de Conclusão do Curso de Administração da Universidade de Brasília da aluna

\section{Camila de Medeiros Escobar}

\author{
Prof. ${ }^{\text {D }}$ Dr. ${ }^{\text {a }}$ Catarina Cecília Odelius \\ Professora-Orientadora \\ Prof. Dr. Francisco Antônio Coelho \\ Júnior \\ Professor-Examinador \\ Prof. Dr. Pedro Paulo Murce \\ Meneses \\ Professor-Examinador
}


À minha família, namorado e amigos, que me ajudaram e me motivaram durante a realização deste trabalho. Foi difícil, mas eu consegui! 
Gostaria de agradecer às pessoas que, de um jeito ou de outro, me ajudaram ao longo dessa jornada. À minha mãe, pelo apoio e amor incondicionais.

À minha família, que esteve sempre presente durante a minha formação e agüentou meus momentos de estresse com muita paciência e carinho.

Ao meu namorado, por ter me apoiado nessa trajetória e por todos os momentos de alegria proporcionados.

À minha orientadora, pela paciência e atenção no decorrer da pesquisa, e aos colegas do grupo de pesquisa, pela cooperação e compartilhamento de experiências.

Às minhas eternas amigas: Aline, Lorena, Thaís, Carol, Pati e Ivna, por todos os momentos de briga e alegria. Sem vocês não teria sido a mesma coisa!

Aos professores do estágio supervisionado, pelas orientações, principalmente à Késia, que foi um anjo comigo.

Obrigada de coração! 
A vantagem é recíproca, pois os homens, enquanto ensinam, aprendem.

(Séneca) 


\section{RESUMO}

O conhecimento é criado a partir da apreensão de informações que, ao serem transmitidas, incorporam crenças e experiências do antigo detentor e são assimiladas pelos indivíduos por meio da aprendizagem. Nesse sentido, a obtenção do conhecimento e o desenvolvimento de habilidades e atitudes tem como resultado a aprendizagem. Os principais objetivos deste estudo foram identificar e descrever os processos de aprendizagem em grupos de pesquisa de diferentes áreas de estudo da Universidade de Brasília e identificar como ocorre a transmissão e o compartilhamento de conhecimento dentro desses grupos. Para isso, foi realizado um estudo de caso, de caráter descritivo, com o uso de um roteiro semi-estruturado de entrevista. As entrevistas foram realizadas com os líderes dos grupos de pesquisa selecionados e foi feita uma análise de conteúdo com base em categorias previamente definidas. Chegou-se a conclusão que há especificidades quanto à produção de conhecimento em grupos que atuam em diferentes áreas de estudo, especialmente em relação à metodologia e coleta de dados, e que o compartilhamento de conhecimento nos grupos ocorre, principalmente, por meio de codificação, em detrimento da socialização e interação entre os membros.

1. Aprendizagem em

Organizações
2. Processos de

Aprendizagem
3. Grupos de Pesquisa 


\section{LISTA DE FIGURAS}

Figura 1: Aquisição e conversão de conhecimento em organizações: modelo proposto por Tacla e Figueredo (2003) .23

Figura 2: Modelo conceitual de impacto do treinamento no trabalho e construtos correlatos.

\section{LISTA DE GRÁFICOS}

Gráfico 1: Faixa etária .36

Gráfico 2: Participação em grupos de pesquisa 37

\section{LISTA DE QUADROS}

Quadro 1: Tempo de formação e número de integrantesErro! Indicador não definido.

Quadro 3: Produção de conhecimento .40

Quadro 4: Motivação para a formação .42

Quadro 5: Seleção de membros. .44

Quadro 6: Competências necessárias .45

Quadro 6: Competências desenvolvidas pelos líderes. .49

Quadro 7: Transmissão e compartilhamento de conhecimentos. .52

Quadro 8: Memória do grupo .52

Quadro 9: Resultados alcançados .54

Quadro 10: Redes sociais .55

Quadro 11: Fatores que contribuem para o sucesso do grupo .56 


\section{LISTA DE ABREVIATURAS E SIGLAS}

CHAs - Conhecimentos, Habilidades e Atitudes

CNPq - Conselho Nacional de Desenvolvimento Científico e Tecnológico

DGP - Diretório dos Grupos de Pesquisa

FAL - Fazenda Água Limpa

HUB - Hospital Universitário de Brasília

IRA - Índice de Rendimento Acadêmico

OMS - Organização Mundial de Saúde

PIBIC - Programa Institucional de Bolsas de Iniciação Científica

PPGA - Programa de Pós-Graduação em Administração

UnB - Universidade de Brasília 


\section{SUMÁRIO}

1 INTRODUÇÃO

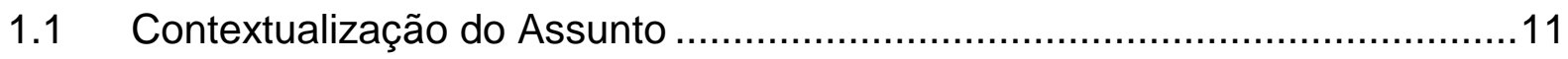

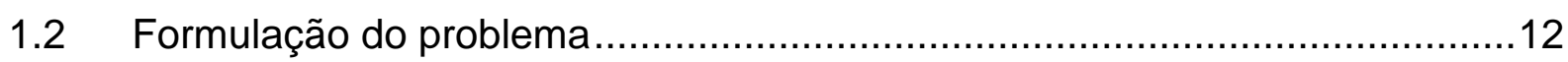

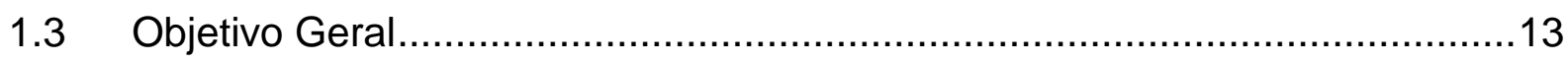

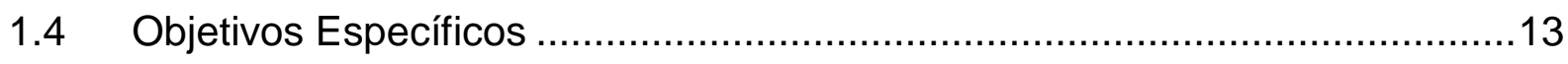

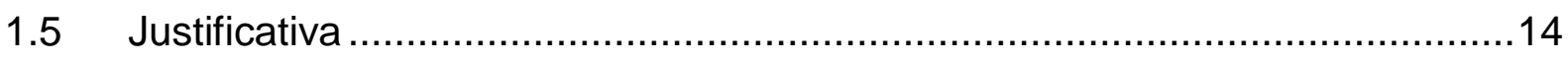

1.6 Métodos e Técnicas de Pesquisa ...........................................................15

1.7 Estrutura e Organização da Monografia ..................................................16

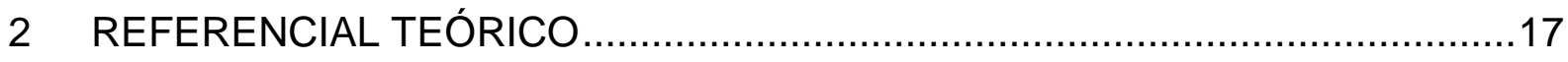

2.1 Aprendizagem em organizações ...........................................................17

2.1.1 Organizações que aprendem .............................................................

2.1.2 Aprendizagem organizacional ........................................................18

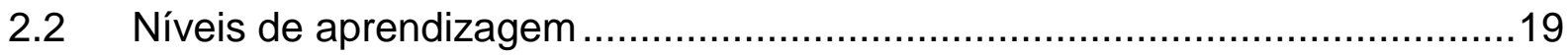

2.3 O conhecimento e os processos de aprendizagem .....................................21

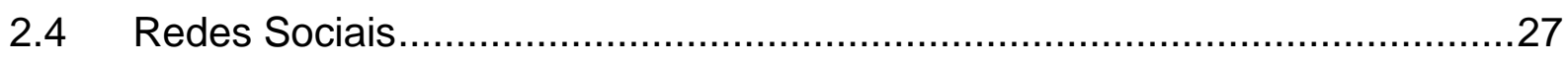

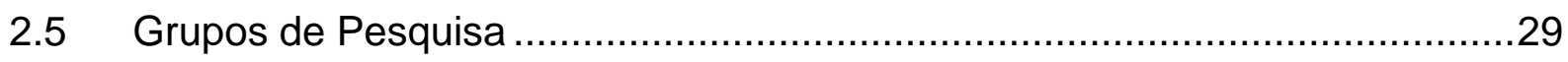

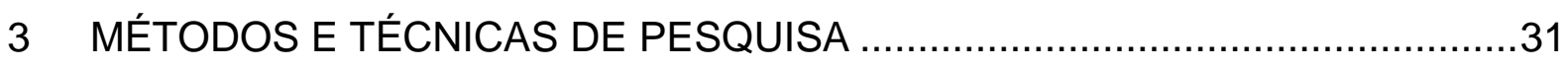

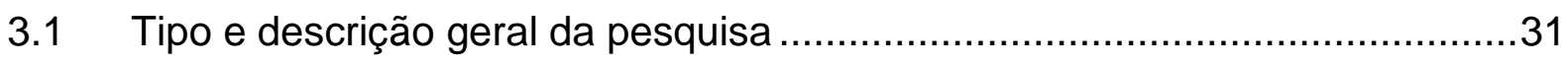

3.2 Caracterização da organização, setor ou área .............................................32

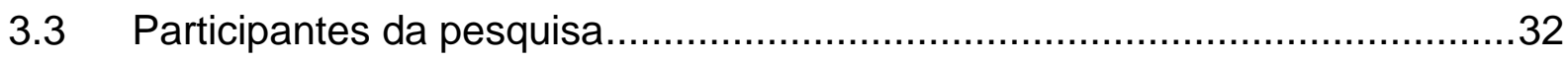

3.4 Caracterização dos instrumentos de pesquisa ...........................................33

3.5 Procedimentos de coleta e de análise de dados .........................................33

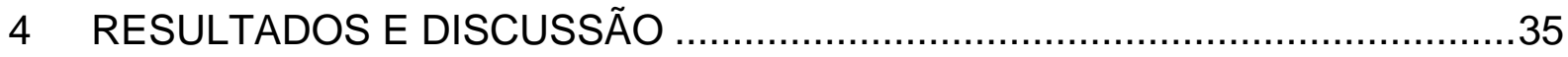

4.1 Características dos participantes da pesquisa .........................................35

4.2 Características dos grupos de pesquisa ...................................................... 
4.2.1 Tempo de formação e número de integrantes .....................................37

4.2.2 Objetivos do grupo e área de atuação ..................................................39

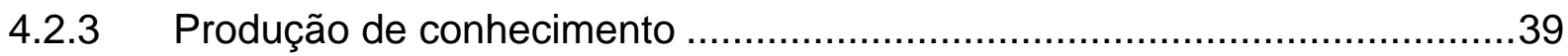

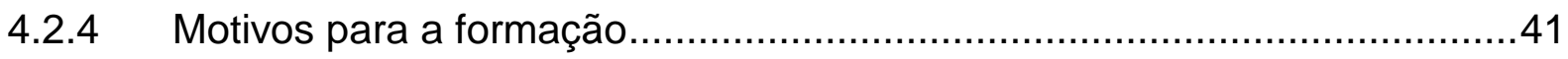

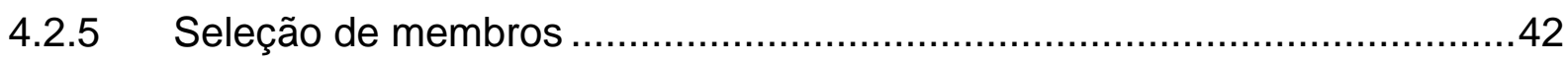

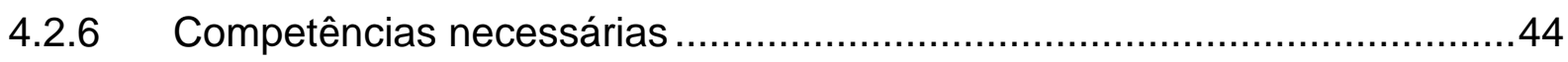

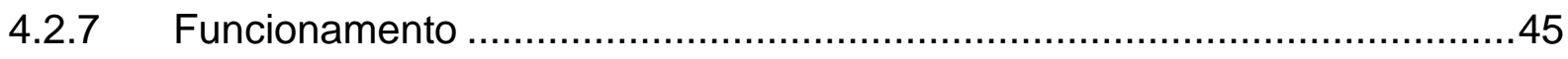

4.2.8 Atividades desenvolvidas pelos alunos......................................47

4.3 Aprendizagem e compartilhamento de conhecimento em grupos de pesquisa 48

4.3.1 Competências desenvolvidas pelo líder ...........................................48

4.3.2 Transmissão e compartilhamento de conhecimentos ..........................49

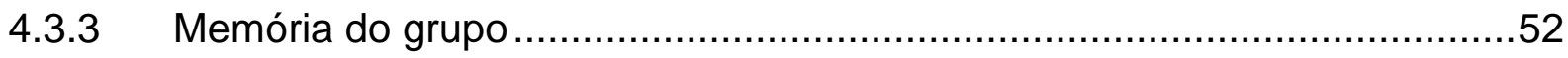

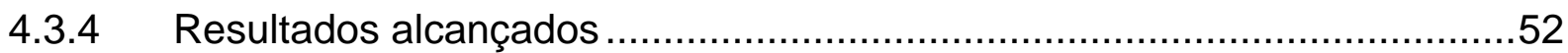

4.3.5 Grupos de pesquisa e suas redes sociais.............................................54

4.3.6 Principais fatores que contribuem para o sucesso do grupo.....................56

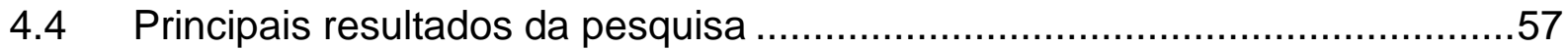

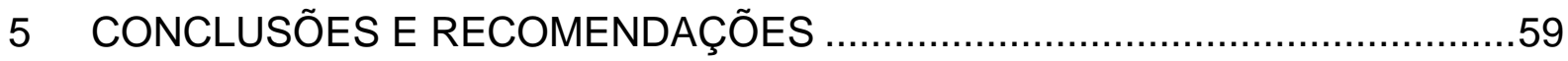

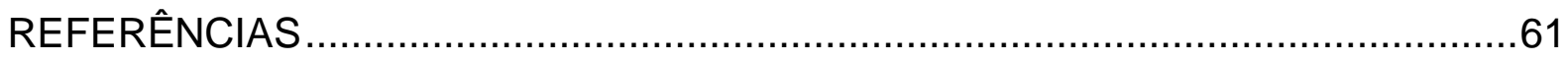

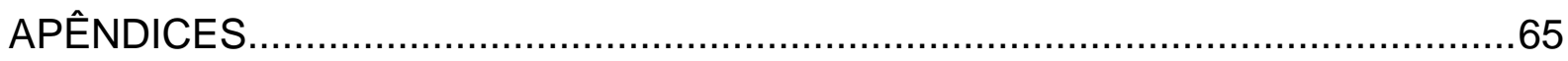

Apêndice $A$ - Convite ao líder para a participação na pesquisa ............................65

Apêndice B - Roteiro semi-estruturado de entrevista ..................................67 


\section{INTRODUÇÃO}

A instabilidade no cenário mundial atual cria a necessidade de novos formatos organizacionais e modelos gerenciais que demandam trabalhadores e gestores dotados de novas competências. É a capacidade de aprender que auxilia no desenvolvimento dessas competências e aumenta as condições de competitividade e sobrevivência das organizações (LOIOLA; NÉRIS; BASTOS, 2006).

A informação e o conhecimento têm tido um novo papel nos processos produtivos, mudando a função desempenhada pelas universidades que, além de serem responsáveis pelo treinamento, passaram a fornecer conhecimento essencial para a evolução de alguns setores (RAPINI, 2007).

Gatti (2005, p. 124) acredita que "o pesquisador não trabalha sozinho, nem produz sozinho". Para a autora, o trabalho em equipe, as redes de troca de idéias e grupos de pesquisa são essenciais para a realização de pesquisas científicas e para o avanço do conhecimento.

Para Strauhs et al. (2001 apud LIMA; AMARAL, 2008, p. 293) "a atuação em grupos de pesquisa é fundamental para a inovação e a criação dos conhecimentos necessários ao desenvolvimento econômico e social". De acordo com Santos (2003), a integração entre os grupos de pesquisa, vinculados à universidades, e as organizações é tida pela aprendizagem organizacional como um suporte para uma estratégia competitiva baseada em inovação.

Neste contexto, o escopo desta pesquisa é a aprendizagem em grupos de pesquisa, enfocando processos de aprendizagem sob a perspectiva dos líderes de cada grupo e o compartilhamento de conhecimento para novos membros do grupo.

\subsection{Contextualização do Assunto}

O cenário atual se caracteriza por rápidas mudanças nos mercados, tecnologias e formas organizacionais. Para acompanhar essas mudanças, torna-se de extrema importância a aquisição de novas competências, ou seja, deve-se 
intensificar a capacidade de indivíduos e organizações aprenderem e transformarem este aprendizado em fator de competitividade. Por este motivo, esta fase tem sido dominada como era da economia baseada no conhecimento e na aprendizagem (LEMOS, 2000).

Pelo fato da aprendizagem ser entendida como catalisadora de processos fundamentais para o êxito organizacional, as pesquisas nessa área têm se configurado como uma proveitosa oportunidade de estudo, uma vez que, na atual sociedade do conhecimento, as pessoas e as organizações precisam aprender constantemente, adequando-se às mudanças sociais e promovendo-as (SOUZASILVA; SCHOMMER, 2008).

A tendência à valorização de um indivíduo que toma decisões, que está em constante aprimoramento, que é criativo e com grande potencial faz com que os processos de aprendizagem se tornem importantes para a compreensão e gestão das organizações (BITENCOURT; AZEVEDO, 2006). Bastos, Gondim e Loiola (2004) confirmam essa idéia, afirmando que a aprendizagem nas organizações surgiu do reconhecimento da importância do processo de aprendizagem e das suas implicações no ambiente de trabalho.

\subsection{Formulação do problema}

De acordo com Acedo et al. (2006 apud ODELIUS; SENA, 2009) alguns estudos realizados no exterior apontam que, nas universidades, o trabalho em equipe aumenta o número de publicações e melhora a qualidade das mesmas. A criação de um grupo de pesquisa é uma das formas de institucionalizar esse trabalho em equipe, por meio de um cadastro realizado junto ao Diretório dos Grupos de Pesquisa (DGP), no Conselho Nacional de Desenvolvimento Científico e Tecnológico (CNPq).

Grupos de pesquisa são formados por pesquisadores, sejam eles professores, estudantes ou técnicos, que possuem interesses de pesquisa em comum. Dentro desses grupos são formadas redes sociais que permitem a interação e o aprendizado entre os diversos membros, assim como a geração e troca de conhecimentos (LEMOS, 2000). 
O conhecimento é criado a partir de informações que, ao serem transmitidas, carregam as crenças e experiências do antigo detentor (TOMAEL; ALCARA; DI CHIARA, 2005). Nesse sentido, a aprendizagem representa um processo de absorção de informações e conhecimento (SANCHEZ; HEENE, 1997 apud CARBONE et al., 2009). Ou seja, a finalidade de um processo de aprendizagem é a obtenção do conhecimento. A compreensão do conceito de aprendizagem depende da compreensão do conceito de conhecimento, e o contrário também acontece (PRANGE, 2001 apud CARBONE et al., 2009).

Abbad e Borges-Andrade (2004) consideram que o processo de aprendizagem ocorre exclusivamente no nível individual. Contudo, seus efeitos podem se propagar para os níveis de grupo e organizacionais. Outros autores, como Cook e Yanow (1996 apud LOIOLA; NÉRIS; BASTOS, 2006), acreditam na existência da aprendizagem organizacional.

Diante do exposto, a presente pesquisa pretende responder às seguintes perguntas: como ocorrem os processos de aprendizagem em grupos de pesquisa? $\mathrm{E}$, como é feita transferência e o compartilhamento de conhecimentos dentro desses grupos de pesquisa?

\subsection{Objetivo Geral}

Identificar e descrever os processos de aprendizagem em grupos de pesquisa de diferentes áreas de estudo da Universidade de Brasília, bem como ocorre a transmissão e o compartilhamento de conhecimento dentro desses grupos.

\subsection{Objetivos Específicos}

- Descrever as características e a dinâmica de funcionamento dos grupos de pesquisa;

- Identificar conhecimentos, habilidades e atitudes necessárias e desenvolvidas na atuação em grupos de pesquisa; 
- Descrever os processos de aprendizagem individuais e coletivos nos grupos de pesquisa;

- Comparar os processos de aprendizagem entre os diferentes grupos de pesquisa;

- Identificar a interação que ocorre com outros grupos de pesquisa ou pessoas de outras áreas de conhecimento.

\subsection{Justificativa}

Conforme Rapini (2007), quanto maior for a contribuição do conhecimento científico ao processo de inovação, mais importante será o papel desempenhado pelas universidades, uma vez que estas são as principais fontes de geração do conhecimento.

Contudo, mesmo sendo produtoras de conhecimento, as universidades, por meio de seus grupos de pesquisa, nem sempre conseguem registrar 0 conhecimento obtido e difundi-lo entre os seus próprios membros (LIMA; AMARAL, 2008).

Autores como Loiola e Bastos (2003a) e Bastos, Gondim e Loiola (2004) acreditam que, apesar do expressivo aumento dos estudos que abrangem a área de aprendizagem organizacional, há carência de reflexões que integrem os níveis em que o processo de aprendizagem ocorre ou pode ocorrer nos contextos organizacionais.

Bastos, Gondim e Loiola (2004, p. 227) afirmam que a pesquisa sobre a aprendizagem nas organizações traria novas contribuições se buscasse esclarecer a maneira com que a "organização cria condições para a ocorrência de aprendizagem com estratégias que procuram elucidar de que modo a pessoa e os grupos aprendem e conseguem provocar mudanças na organização".

De acordo com Loiola e Bastos (2003a), não está sendo devotada atenção suficiente a um dos principais problemas dessa área de pesquisa: como ocorre a passagem do conhecimento do nível individual para o nível coletivo. 
Lima e Amaral (2008) ainda afirmam que pesquisas sobre a utilização de métodos e técnicas de gestão do conhecimento em grupos de pesquisa ainda não foram encontradas, principalmente considerando o contexto de redes sociais.

Além disso, segundo Carvalho, Renaux e Carvalho (2001), grupos de pesquisa apresentam descontinuidades de linhas de fomento e falta de procedimentos escritos sobre projetos, o que dificulta a entrada de novos pesquisadores e trazem prejuízos para a memória do grupo.

Dessa forma, torna-se necessário entender como ocorrem os processos de aprendizagem e como se dá a transferência e o compartilhamento dessa aprendizagem em grupos de pesquisa.

\subsection{Métodos e Técnicas de Pesquisa}

Quanto ao objetivo, esta é uma pesquisa descritiva, pois busca descrever os processos de aprendizagem e como ocorre o compartilhamento de conhecimentos dentro do grupo.

No escopo da pesquisa descritiva, se enquadra em um estudo de caso, pois possui como função principal a descrição e comparação de sete grupos de distintas áreas de conhecimento, escolhidos por disponibilidade, acessibilidade e conveniência.

Com relação à coleta de dados, foi usado um roteiro de entrevista semiestruturado. As entrevistas foram realizadas individualmente com os líderes dos grupos de pesquisa selecionados e gravadas com a autorização dos mesmos.

Quanto ao tratamento dos dados obtidos, a pesquisa é classificada como qualitativa, com uso da análise de conteúdo, em que foram definidas as seguintes categorias: caracterização dos líderes, descrição dos grupos, objetivos dos grupos, motivação para a formação, processo seletivo de novos membros, funcionamento dos grupos, atividades desenvolvidas, produção de conhecimento, competências necessárias, competências desenvolvidas pelos líderes, transmissão e compartilhamento de conhecimentos, memória dos grupos, resultados alcançados, os grupos e suas redes sociais e fatores que contribuem para o sucesso dos grupos. 


\subsection{Estrutura e Organização da Monografia}

O segundo Capítulo explica os principais conceitos referentes à aprendizagem organizacional, de forma a dar embasamento teórico à pesquisa realizada.

O terceiro Capítulo aborda os métodos e técnicas de pesquisa utilizados, define os participantes da pesquisa, o instrumento de coleta de dados e a forma de análise dos dados.

O quarto Capítulo apresenta os resultados obtidos, relacionando-os com o conhecimento acumulado relativo ao tema abordado, além de fazer um comparativo do funcionamento dos grupos de pesquisa de diferentes áreas de conhecimento.

Por fim, o quinto e último Capítulo expõe as considerações finais sobre a pesquisa, as limitações do estudo e as principais questões para trabalhos futuros. 


\section{REFERENCIAL TEÓRICO}

No presente Capítulo serão abordados os principais conceitos relativos ao tema da pesquisa realizada, de modo a dar fundamentação teórica para o alcance dos objetivos propostos.

\subsection{Aprendizagem em organizações}

Apesar do constante reconhecimento da importância do processo de aprendizagem e de suas implicações, percebe-se que não há unanimidade conceitual relativa a esse tema, o que gera uma grande quantidade de definições (SOUZA-SILVA; SCHOMMER, 2008; BASTOS; GONDIM; LOIOLA, 2004).

O campo de aprendizagem em organizações se divide em duas grandes vertentes: a da aprendizagem organizacional, estudada principalmente por pesquisadores acadêmicos, com o objetivo de descrever o processo de aprendizagem nas organizações, e a das organizações que aprendem (learning organizations), desenvolvidas por consultores que buscam descrever e prescrever o que as organizações devem fazer para aprender, com base em experiências anteriores (BASTOS; GONDIM; LOIOLA, 2004).

De acordo com Tsang (1997 apud LOIOLA; BASTOS, 2003b), a aprendizagem organizacional descreve como as organizações aprendem, focalizando os processos de construção e utilização do conhecimento. Já as organizações que aprendem possuem um foco maior na ação e no ajuste de ferramentas específicas que servirão de base para a normalização e prescrição do que as organizações devem fazer para aprender.

A diferença entre as duas vertentes está na forma como abordam o fenômeno da aprendizagem nas organizações. Uma preocupa-se em compreender e analisar, enquanto a outra em mudar e prescrever (BASTOS; GONDIM; LOIOLA, 2004). 


\subsubsection{Organizações que aprendem}

Não há um conceito que defina uma organização que aprende (BASTOS; GONDIM; LOIOLA, 2004). Para Garvin (1993 apud FLEURY, 1995), as organizações que aprendem, ou learning organizations, são definidas como capazes de adquirir, criar e transferir conhecimentos e de modificar o comportamento dos seus membros.

Para Schaw (1994 apud BASTOS; GONDIM; LOIOLA, 2004), uma organização que aprende é aquela que consegue obter conhecimento a partir da comparação de experiências pessoais entre indivíduos diferentes. Para o mesmo autor, o aprendizado ocorre a partir do momento em que as pessoas pensam a respeito das conseqüências dos seus atos, principalmente quando conseguem correlacioná-los a eventos que levam ao sucesso ou ao fracasso organizacional.

Senge (1990 apud BASTOS; GONDIM; LOIOLA, 2004) acredita que

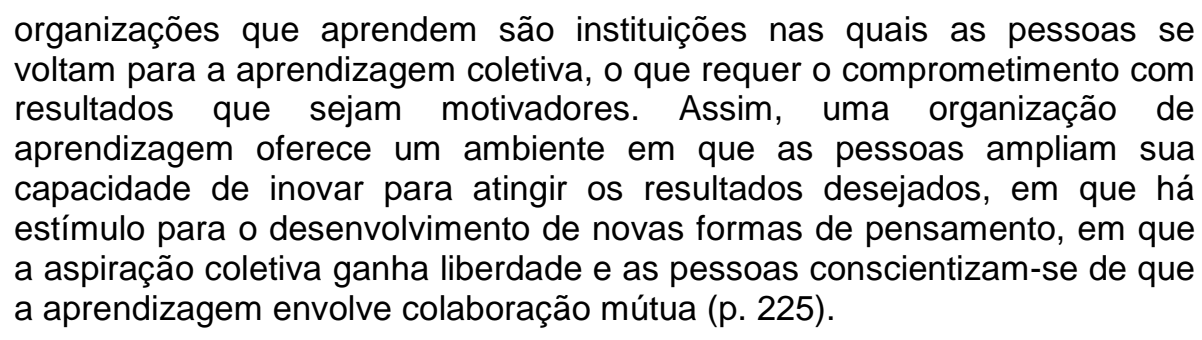

Em suma, os pesquisadores dessa vertente têm o objetivo de identificar os passos necessários para que a aprendizagem organizacional ocorra e de evidenciar os obstáculos, de maneira que as organizações possam gerenciar os próprios processos de aprendizagem (BASTOS; GONDIM; LOIOLA, 2004).

\subsubsection{Aprendizagem organizacional}

A situação apontada no tópico anterior é semelhante para a aprendizagem organizacional, que também não possui um conceito definido. De acordo com Argyris e Schön (1996 apud GUIMARÃES, 2004) aprendizagem organizacional é definida como um conjunto de práticas e procedimentos que auxiliam a empresa a buscar questionar o que foi aprendido, revisando os seus princípios. 
Douglas (1986 apud GUIMARÃES, 2004) crê que o processo de aprendizagem acaba por reestruturar a cultura organizacional, fazendo com que as pessoas compreendam o conhecimento complexo e saibam aplicá-lo ao conhecimento técnico. Assim, acredita-se que aprendizagem e cultura são fatores interdependentes, pois a aprendizagem individual é transferida e compartilhada com outros indivíduos, podendo modificar a cultura e direcionar novas maneiras de pensar e aprender (DOGDSON, 1993 apud GUIMARÃES, 2004).

A pluralidade de conceitos a respeito do tema se dá em virtude da ênfase que os autores dão aos níveis de análise da aprendizagem, que são, principalmente, individual, coletivo e organizacional (PRANGE, 2001 apud BASTOS; GONDIM; LOIOLA, 2004). Alguns autores consideram a aprendizagem organizacional um fenômeno individual, ou seja, consideram que os indivíduos é que aprendem nas organizações. Entretanto, outros defendem que as organizações têm meios de acesso aos conhecimentos produzidos por seus membros, gerando aprendizagem nas organizações (BASTOS; GONDIM; LOIOLA, 2004).

\subsection{Níveis de aprendizagem}

Embora alguns autores, como Gherardi e Nicolini (2001 apud BIDO et al., 2008), considerem que o processo de aprendizagem não ocorre em níveis, outros acreditam que a aprendizagem possa ocorrer nos níveis individual, grupal, organizacional, inter-organizacional e institucional (PAWLOWSKY, 2001; CHAN, 2003 apud BIDO et al., 2008; TEIXEIRA; BEBER; GRZYBOVSKI, 2008). De acordo com Bitencourt e Azevedo (2006), os níveis de aprendizagem mais abordados na literatura são: o individual, o coletivo e o organizacional.

Kim (1998 apud GUIMARÃES, 2004) conceitua a aprendizagem individual como o aumento da capacidade do indivíduo realizar ações eficazes. Já a aprendizagem grupal envolve a construção conjunta de novos conhecimentos e a interação entre vários sistemas e atores. Durante este processo, as pessoas produzem novos conhecimentos que possam ser empregados em diversas situações, a partir do compartilhamento de informações e experiências (VASCONCELOS; MASCARENHAS, 2007 apud TAKAHASHI; FISCHER, 2007). 
Entretanto, apesar de necessária, a aprendizagem individual não é suficiente para a aprendizagem organizacional (GUIMARÃES, 2004). Seria errado concluir que a aprendizagem organizacional é o resultado cumulativo do aprendizado dos membros, pois as organizações possuem normas, valores, ideologias e modelos mentais que se preservam para além da presença de membros individuais (HERDBERG, 1981; ARGYRIS; SCHÖN, 1978 apud SOUZA, 2004). No nível individual, a aprendizagem resulta da intuição e da interpretação do que foi aprendido. No nível coletivo há a integração dos conhecimentos dos indivíduos. Já no nível organizacional ocorre a institucionalização da aprendizagem, que é representada pela formalização e pela rotinização do conhecimento (GUIMARÃES, 2004).

Kim (1993 apud SOUZA, 2004) propõe um modelo integrado de aprendizagem organizacional, em que consta a noção de modelos mentais. Para o mesmo autor, a noção de modelos mentais é vista como uma síntese entre as crenças individuais e as compartilhadas, ou seja, os modelos mentais estão fortemente ligados à cultura organizacional e representam os resultados das aprendizagens dos indivíduos, pois transcendem à memória organizacional.

Diante disso, para Kim (1998 apud BASTOS; GONDIM; LOIOLA, 2004), a aprendizagem individual ocorre a partir da reflexão a respeito de experiências pessoais que gera modelos e rotinas pessoais de trabalho. Assim, passa a existir aprendizagem organizacional no momento em que a organização passa a disseminar e favorecer o compartilhamento desses modelos e rotinas.

Para Bastos, Gondim e Loiola (2004):

a aprendizagem passa a ser organizacional no momento em que, transcendendo a cada indivíduo em particular, os conhecimentos, as atitudes, as visões e as práticas tornam-se compartilhados pelo coletivo ( $p$. 224).

Probst e Büchel (1997 apud BASTOS; GONDIM; LOIOLA, 2004) acreditam que ocorre a aprendizagem organizacional em três circunstâncias: quando há mudança das estruturas cognitivas e dos comportamentos no nível do grupo; quando se constata mudança no conhecimento e nos valores coletivos; e quando são observadas alterações nos comportamentos habituais partilhados coletivamente.

De acordo com os mesmos autores, são necessárias comunicação, transparência e integração interpessoal para que a aprendizagem individual atinja o 
nível organizacional. É por meio desses fatores que os indivíduos exteriorizam suas crenças e valores, que passarão a ser compartilhados pelo grupo. Desse modo, a aprendizagem no nível individual poderá ser compartilhada coletivamente. Souza (2004, p. 7) acredita que "a aprendizagem individual não é sinônimo de aprendizagem organizacional, contudo não haverá aprendizagem organizacional sem a aprendizagem individual".

Apesar de autores como Takahashi e Fischer (2007) acreditarem que a aprendizagem ocorre principalmente do nível individual para o organizacional, Bitencourt (2001) não confirma esse pressuposto. De acordo com a autora, a aprendizagem coletiva não se inicia necessariamente pela aprendizagem individual: ela pode ser desencadeada no ambiente do próprio grupo.

Corroborando essa idéia, Schultz (1993 apud TAKAHASHI; FISCHER, 2007) afirma que a aprendizagem organizacional pode inibir a aprendizagem individual, quando envolve freqüentes modificações e atualização das regras (essas modificações evitam que experiências suficientes sejam intensificadas e assimiladas), e que a recíproca também é verdadeira, quando o ajuste de regras envolve a invalidação de competências acumuladas, pois os indivíduos procuram resistir à invalidação das competências já adquiridas.

Dessa forma, não se pode inferir necessariamente que uma aprendizagem é anterior à outra, embora haja um consenso de que existem diferentes níveis de aprendizagem e que estes estão relacionados entre si (COOK; YANOW, 1993 apud TAKAHASHI; FISCHER, 2007).

\subsection{O conhecimento e os processos de aprendizagem}

O conceito de conhecimento é fundamental para a compreensão dos processos de aprendizagem organizacional (LOIOLA; NÉRIS; BASTOS, 2006).

Miranda (1999) classificou os tipos de conhecimento em explícito, tácito e estratégico. O conhecimento explícito é definido como o conjunto de informações contidas em algum material (livro, por exemplo) que caracteriza o conteúdo disponível sobre o tema específico. O conhecimento tácito é visto como o acúmulo de conhecimento prático agregado à experiência e à personalidade da pessoa que o 
detém. E, para finalizar, o conhecimento estratégico é a combinação dos dois conhecimentos explicados anteriormente, formados a partir de informações estratégicas.

Ainda com relação aos tipos de conhecimento, Lemos (2000) divide o conhecimento em dois tipos: o conhecimento codificado (ou explícito) e o tácito (ou implícito). O conhecimento codificado é aquele que pode ser transformado em uma mensagem, podendo ser manipulado como uma informação, sendo facilmente transferido. Em contrapartida, o conhecimento tácito não pode ser transferido com facilidade, pois se refere a conhecimentos implícitos a um ser, como as habilidades acumuladas por um indivíduo, organização ou um conjunto delas, que compartilham de atividades e linguagem comum.

De acordo com Lemos (2000), ambos os conhecimentos devem ser tratados como complementares, pois sempre haverá alguma forma de conhecimento específico implícito nas práticas de cada organização. Dessa forma, não podem ser tratados de maneira substitutiva ou excludente. Entretanto, é válido ressaltar que boa parte do conhecimento compartilhado em uma organização é tácito, o que aumenta a importância da transmissão do saber e aprendizagem socioculturais (NONAKA, 1994 apud SOUZA, 2004).

Loiola, Néris e Bastos (2006) afirmam que a distinção entre os tipos de conhecimentos é importante para a compreensão de processos de geração, de difusão e de transferência de conhecimento organizacional. Popper e Lipshitz (2000 apud LOIOLA; NÉRIS; BASTOS, 2006) acreditam que a transferência, ou institucionalização do conhecimento individual, representa o próprio fenômeno da aprendizagem organizacional. Conforme os mesmos autores, para que a aprendizagem organizacional ocorra, os indivíduos precisam desenvolver e disseminar o conhecimento nos múltiplos níveis da organização (individual, grupal e organizacional).

A aprendizagem em organizações, segundo o modelo proposto por Tacla e Figueredo (2003 apud NÉRIS; LOIOLA, 2006), refere-se a dois processos interdependentes e dinâmicos: aquisição e conversão do conhecimento. A aquisição de conhecimento pelos indivíduos se classifica em aquisição de conhecimentos internos e externos. Já a conversão dos conhecimentos do nível individual para o organizacional se subdivide em socialização e codificação, como mostra a Figura 1. 


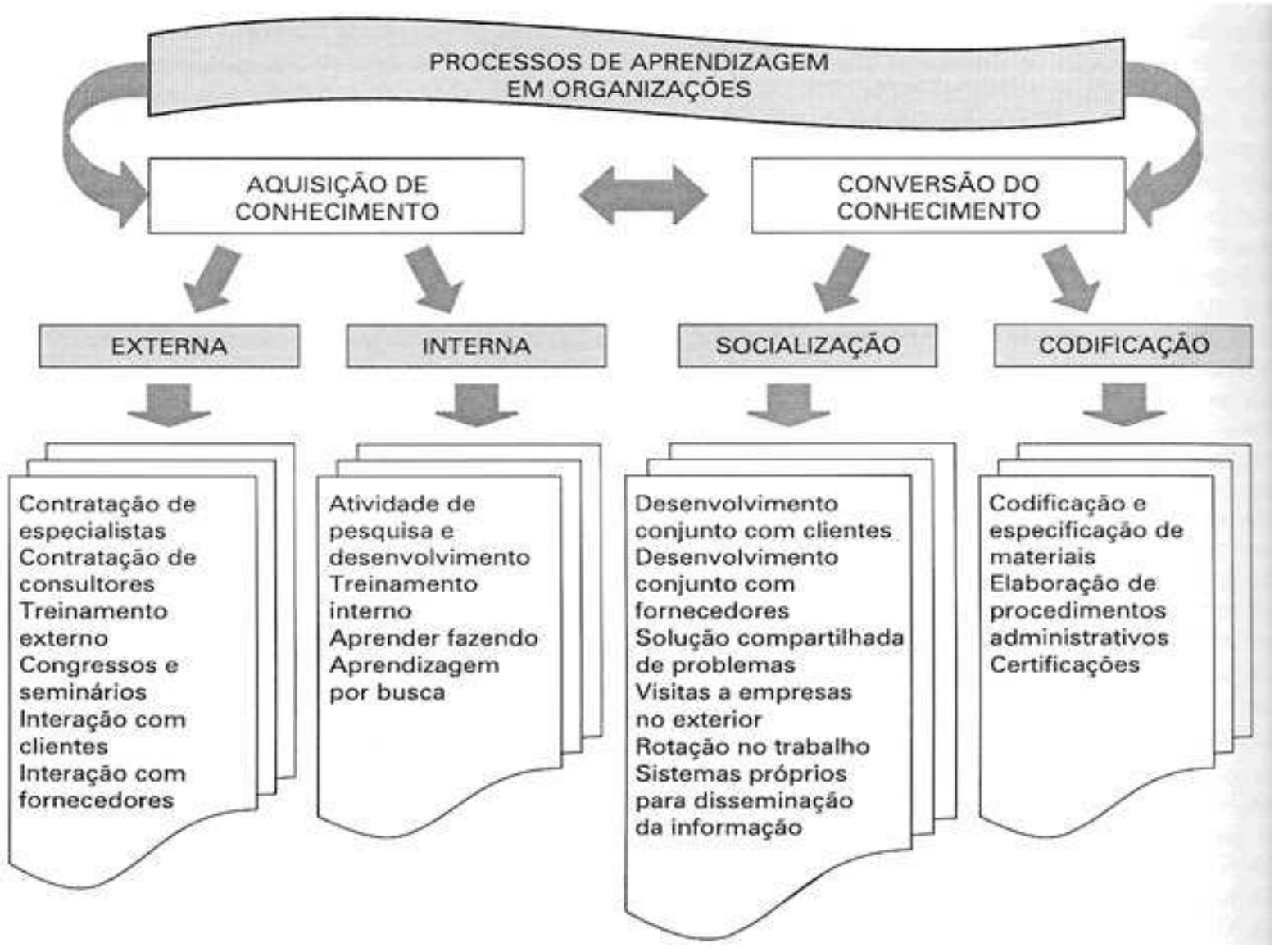

Figura 1: Aquisição e conversão de conhecimento em organizações: modelo proposto por Tacla e Figueredo (2003)

Fonte: Tacla e Figueredo (2003 apud LOIOLA; NÉRIS; BASTOS, 2006)

Tacla e Figueredo (2003 apud LOIOLA; NÉRIS; BASTOS, 2006, p. 125) concluíram que "o aprendizado depende da variedade, do grau de interação e da intensidade de uso das fontes internas e externas de conhecimento". Para Antonelli (2002 apud LOIOLA; NÉRIS; BASTOS, 2006), quanto mais novo o conhecimento requerido, maior será a probabilidade de busca de conhecimentos externos à organização. Entretanto, quanto mais específico o conhecimento desejado, maior incentivo para a internalização deste conhecimento.

Entre as razões para a busca de conhecimento externo à organização, estão: "o aumento do volume de conhecimentos envolvido nos processos decisórios e a exploração de novos conhecimentos associados a novas tecnologias". Os tipos de aprendizado, quando adquiridos externamente, são: aprendizado pela imitação, aprendizado pela interação e aprendizado pela cooperação (LOIOLA; NÉRIS; BASTOS, 2006, p. 125).

Considerando a natureza do conhecimento (explícita ou tácita) e o volume que se busca, Anand, Glick e Manz (2002) afirmam que o conhecimento explícito, 
quando almejado em pequenas quantidades, pode ser obtido por meio de processos informais que dispensam interações mais intensas, como e-mails, palestras, conversas por telefone e outros. Todavia, quando desejado em grandes volumes, geralmente quando se está relacionado ao fornecimento de informações rotineiras e facilmente compreensíveis, é comum as organizações utilizarem intercâmbio eletrônico de informações (ANAND; GLICK; MANZ, 2002). O conhecimento, quando codificado, "permite ser armazenado, memorizado, transacionado e transferido, além de poder ser reutilizado, reproduzido e comercializado, indefinidamente, a custos extremamente baixos" (LEMOS, 2000, p. 165).

Já o conhecimento tácito, de acordo com Anand, Glick e Manz (2002), mesmo em pequenas quantidades, exige interações mais intensas. Lemos (2000) afirma que o conhecimento tácito só é compartilhado por meio da interação humana. Para isso, as organizações podem fazer uso de equipes interorganizacionais, por exemplo. Entretanto, para a aquisição de conhecimentos não-rotineiros e complexos em grande quantidade, são necessárias fortes interações pessoais, como alianças estratégicas ou redes organizacionais (ANAND; GLICK; MANZ, 2002).

Como foi observado, o conhecimento tácito e o explícito podem ser adquiridos por meio de fontes externas à organização. Porém, há uma demanda maior de tempo para que haja a transferência do conhecimento tácito, uma vez que é exigida uma interação mais forte entre as partes; e algumas vezes são criadas barreiras, quando o assunto em questão é o conhecimento estratégico, para impedir o acesso dos concorrentes (NÉRIS; LOIOLA, 2006). É importante enfatizar que "é a interação entre o conhecimento tácito e o explícito que permitirá a criação de novos conhecimentos" (TOMAEL; ALCARA; DI CHIARA, 2005, p. 97). Posto isso, fazem-se necessárias fontes internas de conhecimento para que os indivíduos aprendam.

Segundo Abbad e Borges-Andrade (2004) a aprendizagem interna se divide em natural e induzida. A natural ocorre de maneira informal, por meio de mecanismos como a observação, imitação, tentativa e erro, contatos informais com colegas, entre outros. A aprendizagem induzida segue uma lógica formal e sistemática, criada para melhorar os processos de aquisição, manutenção e generalização de conhecimentos, habilidades e atitudes (CHAs).

Atualmente, alguns mecanismos de conhecimento interno têm sido bastante valorizados, tais como: aprender fazendo (learning by doing), aprender com a mudança (learning by changing), aprender pela análise de desempenho, aprender 
pelo treinamento (learning through training) aprender pela pesquisa (learning by searching) e aprender pelo uso (NÉRIS; LOIOLA, 2006). Contudo, é necessária uma capacitação adequada, por meio do aprendizado constante, para que os indivíduos e organizações enfrentem as mudanças do cenário atual (LEMOS, 2000).

A aquisição do conhecimento contempla uma etapa do processo de aprendizagem organizacional. No entanto, a aquisição individual do conhecimento não assegura uma aprendizagem organizacional (NÉRIS; LOIOLA, 2006). Para estes autores

conhecimentos adquiridos pelos indivíduos são transformados em conhecimento organizacional por meio de subprocessos de conversão, embora nem tudo o que o indivíduo aprende é passível de ser transformado em conhecimento organizacional, o qual, ainda assim, é maior do que a soma dos conhecimentos individuais (p. 4).

O subprocesso de conversão do conhecimento individual para 0 organizacional, de acordo com Néris e Loiola (2006), se subdivide em socialização e codificação do conhecimento.

Nonaka e Takeuchi (1997 apud NÉRIS; LOIOLA, 2006, p. 4) definem socialização como um "processo de interação entre indivíduos que, ao partilharem determinada experiência de trabalho, operam a conversão de conhecimento tácito de indivíduos em conhecimento tácito compartilhado". Além disso, a ênfase no processo de socialização do conhecimento se dá devido à impossibilidade de um único indivíduo ter uma visão completa de todo um processo (NÉRIS; LOIOLA, 2006).

Cabe ressaltar que "a socialização dos conhecimentos da organização é facilitada quando tais conhecimentos estão explicitados em formas de normas e rotinas, isto é, estão codificados" (NÉRIS; LOIOLA, 2006, p. 5). De acordo com os mesmos autores, a codificação de conhecimentos assegura que tais informações permaneçam na organização, mesmo que o quadro funcional seja alterado, permitindo que novas pessoas tenham acesso a esses conhecimentos ou que esses registros possam ser resgatados pelos mesmos indivíduos futuramente.

Dessa forma, os processos de socialização e codificação devem coexistir, uma vez que a codificação dos conhecimentos facilita a transferência de aprendizagem do nível individual para o organizacional, bem como a socialização que, por meio da troca de experiências, faz com que a codificação adquira um caráter organizacional (NÉRIS; LOIOLA, 2006). Figueiredo (2002 apud NÉRIS; 
LOIOLA, 2006) define a codificação como uma maneira para formatar o conhecimento tácito.

A aprendizagem dos indivíduos e a sua transformação em aprendizagem organizacional dependem da variedade, do grau de interação e da intensidade de uso das fontes internas e externas de conhecimento e da socialização e codificação do que foi aprendido pelos indivíduos nas empresas (TACLA; FIGUEREDO, 2003 apud LOIOLA; NÉRIS; BASTOS, 2006).

Como já dito anteriormente, "a aprendizagem organizacional é vista como a busca de manter e desenvolver competitividade, produtividade e inovação em condições tecnológicas e de mercado incertas". Cada organização possui momentos e situações que privilegiam a aprendizagem, dependendo de sua cultura organizacional (SOUZA, 2004, p. 7).

Weick e Westley (1996 apud SOUZA, 2004, p. 9) observam que "os momentos de aprendizagem ocorrem em diferentes contextos". Considerando a aprendizagem coletiva, a aprendizagem se dará com a interação e construção de sentidos coletivos, produzindo um novo patamar de conhecimento.

Pilati e Abbad (2005) definem aquisição, retenção e generalização como os componentes do processo de aprendizagem e os relacionam aos conceitos de transferência de aprendizagem e impacto do treinamento no trabalho.

Segundo os mesmos autores, todos esses conceitos são interdependentes e acontecem de maneira hierárquica. Aquisição é o processo básico de apreensão de conhecimentos, habilidades e atitudes e é condição básica para que os próximos processos aconteçam. Retenção é o processo posterior à aquisição e, como a palavra já diz, se refere à retenção ou armazenamento dos CHAs na memória de longo prazo. Generalização é entendida como o grau em que os CHAs adquiridos são utilizados fora dos contextos em que foram aprendidos, ou seja, é essencial para que o que foi aprendido possa ser aplicado no contexto organizacional.

A transferência de aprendizagem é vista por Pilati e Abbad (2005) como o uso, no ambiente de trabalho, de competências e desempenhos específicos aprendidos. Por último, o impacto do treinamento no trabalho diz respeito ao efeito provocado no desempenho e na motivação do indivíduo na execução do seu papel na organização. 
A Figura 2 procura esquematizar o conjunto desses termos, organizados de forma hierárquica, devido ao estreito relacionamento conceitual que mantêm entre si.

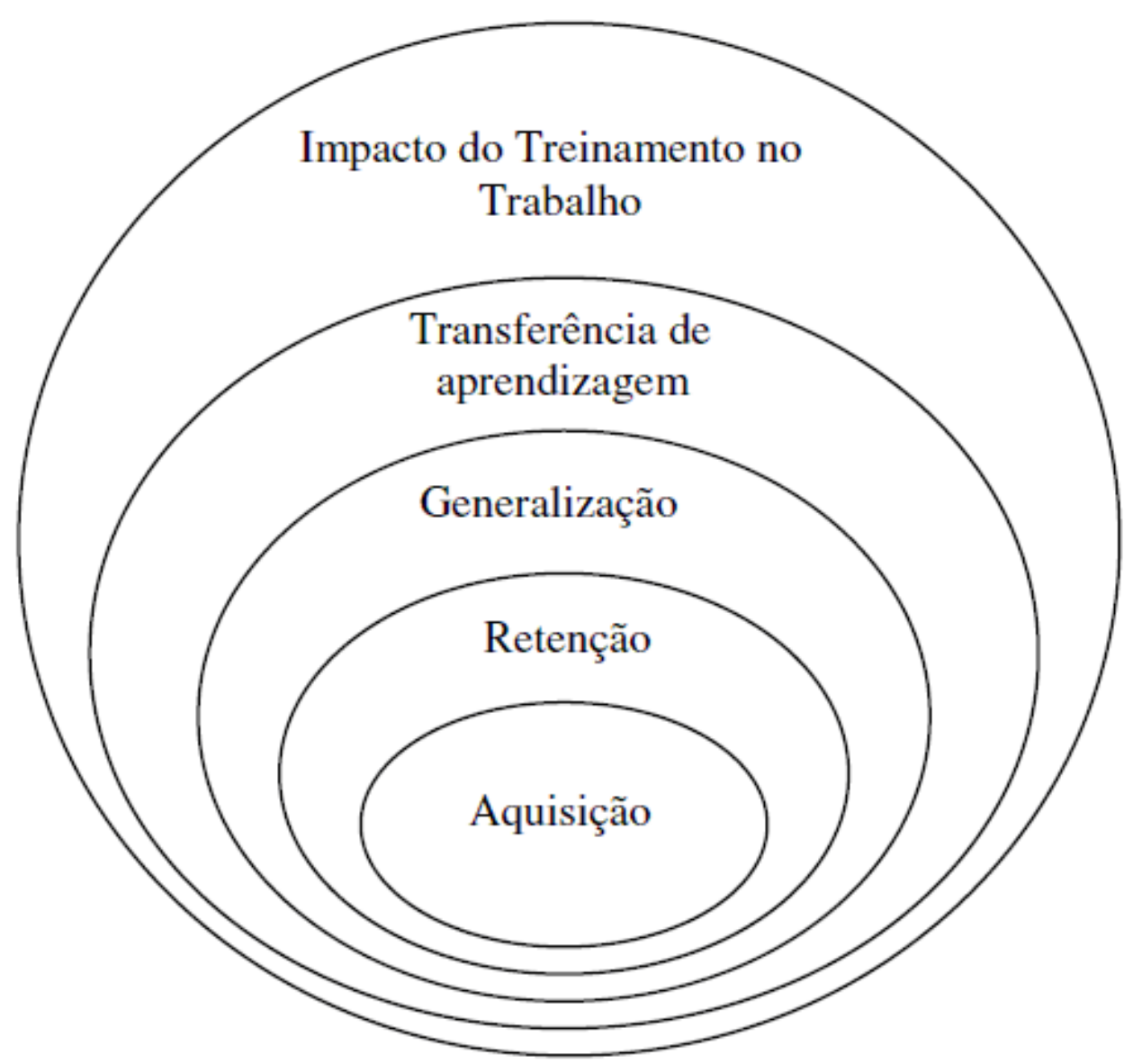

Figura 2: Modelo conceitual de impacto do treinamento no trabalho e construtos correlatos. Fonte: Pilati e Abbad (2005, p. 44).

A aprendizagem representa um processo que muda $O$ status do conhecimento (SANCHEZ; HEENE, 1997 apud CARBONE et al., 2009). Em concordância com essa informação, Prange (2001 apud CARBONE et al., 2009, p. 84) afirma que "a essência do processo de aprendizagem é o conhecimento" e complementa: "a compreensão de um conceito depende da compreensão do outro".

\subsection{Redes Sociais}

Considerando a era da economia baseada no conhecimento e no aprendizado, considera-se "a formação de redes como o formato organizacional 
mais adequado para promover o aprendizado intensivo para a geração de conhecimento e inovações" (LEMOS, 2000, p. 169).

Segundo Marteleto (2001) as redes sociais são representadas pela união de idéias e recursos em prol de valores e interesses comuns à um conjunto de indivíduos. Nas redes sociais, cada pessoa tem sua função e identidade cultural. As relações entre esses indivíduos formam as redes sociais (TOMAEL; ALCARA; DI CHIARA, 2005).

No meio empresarial, as organizações são tidas como um conjunto de atores sociais ligados por meio de um conjunto de relações sociais de um tipo específico (BURT, 2000 apud GOMES; ODELIUS; ZANCAN, 2007). "Funcionam como espaços para o compartilhamento de informações e do conhecimento" (TOMAEL; ALCARA; DI CHIARA, 2005, p. 94).

As redes nas organizações podem surgir de diversas formas (conversas informais, encontros fora do ambiente de trabalho, reuniões, congressos e outros) que, de acordo com a finalidade de cada uma, são subdivididas em: redes de confiança, redes de trabalho ou consulta e redes de comunicação (KRACKHARDT; HANSON, 1999 apud TOMAEL; ALCARA; DI CHIARA, 2005).

Nas redes de confiança são compartilhadas informações restritas a algumas pessoas. As redes de trabalho têm o objetivo de facilitar a troca de informações que auxiliem no exercício do trabalho. E, por último, as redes de comunicação possibilitam a troca regular de informações pertinentes ao trabalho (KRACKHARDT; HANSON, 1999 apud TOMAEL; ALCARA; DI CHIARA, 2005).

Este formato organizacional é visto como a forma mais completa para permitir a interação e o aprendizado, assim como a geração e troca de conhecimento (LEMOS, 2000). "As redes sociais dependem da interação dos diversos atores - internos e externos à organização - dispostos a compartilhar informações e experiências, visando o aprendizado organizacional [...]" (TOMAEL; ALCARA; DI CHIARA, 2005, p. 101).

De acordo com Tomael, Alcara e Di Chiara (2005):

as redes sociais são recursos importantes para a inovação, em virtude de manterem canais e fluxos de informação em que a confiança e o respeito entre os atores os aproximam e os levam ao compartilhamento de informações que incide no conhecimento detido por eles, modificando-o ou ampliando-o (p. 102). 
A participação em redes pode proporcionar diversos tipos de experiências, como a troca de informações e a transmissão de conhecimento explícito ou tácito, estimulando o aprendizado e gerando o conhecimento coletivo (LEMOS, 2000). Lemos (1996 apud LEMOS, 2000) ainda ressalta que as instituições de ensino e pesquisa são importantes para o desenvolvimento deste conhecimento conjunto.

\subsection{Grupos de Pesquisa}

De acordo com Lima e Amaral (2008, p. 291), "a complexidade das novas tecnologias exige um esforço cada vez maior das empresas e instituições de pesquisa". Diante disso, a formação de redes de pesquisa tem sido cada vez mais estimulada e valorizada por governos, instituições de apoio à pesquisa, empresas e pesquisadores (CANONGIA et al., 2004).

Redes de pesquisa também podem ser denominadas de grupos de pesquisa, laboratório acadêmico, laboratório de ensino, laboratório de pesquisa ou laboratório de desenvolvimento (RENAUX et al., 2001 apud LIMA; AMARAL, 2008).

Um grupo de pesquisa, de acordo com o CNPq (2009), é definido como um conjunto de pessoas organizadas em torno de um ou mais objetos de estudo, em que há envolvimento profissional e permanente com atividades de pesquisas.

Um grupo de pesquisa é organizado hierarquicamente em torno de uma ou, eventualmente, duas lideranças. O pesquisador líder de grupo é a pessoa que detém a liderança acadêmica e intelectual naquele ambiente de pesquisa. Normalmente, tem a responsabilidade de coordenação e planejamento dos trabalhos de pesquisa do grupo. Sua função aglutina os esforços dos demais pesquisadores e aponta horizontes e novas áreas de atuação dos trabalhos.

Geralmente, o grupo é composto por professores pesquisadores, por estudantes de graduação, pós-graduação e técnicos de nível superior. O grupo deve pertencer a uma instituição previamente autorizada pelo CNPq. O estudo, normalmente, se organiza em torno de linhas comuns de pesquisa e há compartilhamento de instalações e equipamentos (CNPq, 2009).

A principal missão de um grupo de pesquisa consiste em gerar conhecimento. Contudo, devido à grande rotatividade dos seus integrantes, 
principalmente quando os alunos concluem o curso de graduação ou pósgraduação, há perda de competências, formadas pela união dos conhecimentos e experiências de todos os pesquisadores (RENAUX et al., 2001 apud LIMA; AMARAL, 2008).

Entretanto, embora produtoras de conhecimento, as organizações de fomento à pesquisa nem sempre conseguem registrar, de maneira adequada, 0 conhecimento gerado e difundí-lo interna e externamente (LIMA; AMARAL, 2008). A participação do coordenador e de pesquisadores mais experientes na transmissão de conhecimentos básicos é essencial e decisiva no processo de aprendizagem (MUNDIM, 2001 apud LIMA; AMARAL, 2008).

Quase todos os grupos de pesquisa em atividade existentes no país estão cadastrados em uma base de dados, desenvolvida no CNPq desde 1992, chamada Diretório dos Grupos de Pesquisa (DGP). As principais finalidades do DGP são: ser instrumento para o intercâmbio e troca de informações para as comunidades científicas; ser ferramenta para o planejamento e a gestão das atividades de ciência e tecnologia; e, preservar a memória da atividade científico-tecnológica no Brasil (CNPq, 2009).

Alguns estudos realizados no exterior indicam que a quantidade e a qualidade de pesquisas científicas e de artigos publicados em revistas e congressos aumentam com o trabalho em equipe (ACEDO et al., 2006 apud ODELIUS; SENA, 2009).

A formalização dos grupos de pesquisa no país, por meio do DGP, é uma prática que tem consolidado a pesquisa no Brasil. Esses grupos formam inúmeros pesquisadores e são responsáveis por grande parte das pesquisas realizadas atualmente (MARAFON, 2008). De acordo com o mesmo autor, os grupos de pesquisa podem se tornar o diferencial na formação profissional, possibilitando a soma de conhecimentos e experiências práticas. 


\section{MÉTODOS E TÉCNICAS DE PESQUISA}

Neste Capítulo são apresentadas informações relativas aos tipos de pesquisa, instrumento de coleta de dados, procedimentos para a coleta e análise dos dados, bem como há a descrição dos participantes da pesquisa.

\subsection{Tipo e descrição geral da pesquisa}

Esta pesquisa faz parte de uma pesquisa maior que o grupo Aprendizagem em Organizações, do Programa de Pós-Graduação em Administração (PPGA) da Universidade de Brasília (UnB) está desenvolvendo. Em 2008, foi realizada uma pesquisa-piloto, com dois grupos de pesquisa do Instituto de Psicologia, em que foram obtidos alguns dados. Com o objetivo de expandir a pesquisa e aprofundar os resultados alcançados, esta nova coleta de dados está sendo realizada com três grupos de cada uma de oito áreas de conhecimento, ou seja, 24 grupos de pesquisa da UnB, com o objetivo de descrever os processos de aprendizagem, compartilhamento de conhecimento e relações em rede em grupos de pesquisa da UnB.

Esta é uma pesquisa descritiva, pois tem o objetivo de identificar os processos de aprendizagem e descrever como ocorre o compartilhamento de conhecimento para novos membros dos grupos de pesquisa. De acordo com Marconi e Lakatos (2007), uma pesquisa descritiva tem como objetivo a descrição das características de determinada população ou fenômeno.

Dentro do estudo descritivo, a pesquisa se enquadra no subgrupo estudo de caso, pois possui, como função principal, a descrição de certas características de populações, utilizando técnicas de amostragem que apresentem caráter representativo.

Quanto ao tratamento dos dados, a pesquisa é classificada como qualitativa, pois este tipo de pesquisa permite compreender melhor o caráter complexo e multidimensional de certos fenômenos (ANDRÉ, 1983), no caso, os processos de aprendizagem dentro de grupos de pesquisa. 
E, por último, segundo o método de abordagem, esta é uma pesquisa de campo, posto que permite o contato direto com os participantes da pesquisa, que são as principais fontes de dados necessários para a análise, e uma pesquisa documental, pois foram realizadas consultas ao DGP, CNPq e Currículos Lattes dos entrevistados.

\subsection{Caracterização da organização, setor ou área}

De acordo com consulta realizada no DGP, no sítio eletrônico do CNPq, a UnB possui, atualmente, 324 grupos de pesquisa ativos e inscritos no Diretório.

Esses grupos se dividem em oito grandes áreas de conhecimento: Ciências Agrárias, com 20 grupos; Ciências Biológicas, com 32; Ciências da Saúde, também com 32; Ciências Exatas e da Terra, com 37; Ciências Humanas, com 77; Ciências Sociais e Aplicadas, com 67; Lingüística, Letras e Artes, com 24; e, por último, Engenharias, com 35 grupos.

Cada grupo contém, pelo menos, um coordenador, geralmente professor com doutorado, responsável pelo grupo de pesquisa, e pode vir a ter como membros outros professores, estudantes de graduação e pós-graduação e técnicos.

\subsection{Participantes da pesquisa}

Os coordenadores de três grupos de cada grande área de conhecimento foram convidados a participar da pesquisa que está sendo realizada pelo grupo de Aprendizagem em Organizações.

Para esta pesquisa foram selecionados, por conveniência, acessibilidade e disponibilidade, os líderes de sete grupos de pesquisa pertencentes a distintas áreas de conhecimento: Ciências Biológicas (G1), Ciências Agrárias (G2), Ciências da Saúde (G5), Ciências Sociais e Aplicadas (G6), Lingüística, Letras e Artes (G8), Engenharias (G9) e Ciências Exatas e da Terra (G11). Para os coordenadores dos grupos da área de Ciências Humanas foram enviados convites, contudo não foram obtidas respostas. 
Cada grupo recebeu um código, de forma a identificá-lo no decorrer da pesquisa, sendo que, neste estudo, nem todos os grupos pesquisados pelo grupo de Aprendizagem Organizacional compõem a amostra, o que faz com que a numeração dos códigos não corresponda a uma seqüência completa.

\subsection{Caracterização dos instrumentos de pesquisa}

Foi utilizado para a coleta de dados desta pesquisa um roteiro semiestruturado de entrevista (APÊNDICE B), em que constavam perguntas a respeito dos objetivos do grupo, do seu surgimento, forma de funcionamento, mudança no repertório de conhecimento, entre outras.

Este roteiro foi elaborado pelos integrantes do grupo de Aprendizagem em Organizações, tomando como base o roteiro que havia sido aplicado na pesquisapiloto realizada pelo grupo em 2008. A autora deste estudo integra o grupo Aprendizagem em Organizações e participou da elaboração desse roteiro.

\subsection{Procedimentos de coleta e de análise de dados}

O contato inicial com os grupos foi feito com os coordenadores, por meio de correio eletrônico (APÊNDICE A). Foram enviados convites padronizados, em que foram explicados os objetivos da pesquisa e foi questionado se os coordenadores tinham interesse em participar da mesma.

As entrevistas com os líderes foram realizadas individualmente, em diferentes datas, no período de 15 de outubro à 10 de novembro, e gravadas, com a autorização dos entrevistados, para posterior transcrição e análise dos dados coletados.

Para a análise dos dados foi utilizada a análise de conteúdo. De acordo com Krippendorff (1980 apud ANDRÉ, 1983), análise de conteúdo é tida como uma técnica de redução, em categorias, de um certo volume de dados coletados, para que as informações possam ser melhor examinadas. As categorias são definidas a partir de padrões relevantes. 
As principais categorias identificadas nesta pesquisa foram: caracterização dos grupos, atividades desenvolvidas, produção de conhecimento, competências necessárias e adquiridas, transmissão e compartilhamento de conhecimento, memória do grupo e resultados alcançados (individuais e do grupo). 


\section{RESULTADOS E DISCUSSÃO}

Neste Capítulo serão apresentadas as características dos participantes da pesquisa, as características dos grupos dos quais fazem parte e os processos de aprendizagem, fazendo um comparativo entre cada grupo para identificar suas semelhanças e diferenças.

\subsection{Características dos participantes da pesquisa}

A seguir, são apresentadas algumas características sociodemográficas e alguns dados dos líderes entrevistados, como o gênero, faixa etária, grau de instrução e participação em grupos de pesquisa. Estes dados foram obtidos tanto das entrevistas, como dos Currículos Lattes dos professores no sítio eletrônico do CNPq.

Dos grupos pesquisados, os líderes do G2, G5, G6 e G8 são mulheres e os do G1, G9 e G11 são homens. Percebe-se que, com exceção do G2, as áreas voltadas para as disciplinas de exatas possuem líderes homens, enquanto que as áreas de humanas e saúde possuem líderes mulheres.

Quanto à faixa etária, verificou-se que três coordenadores encontram-se na faixa entre 40 e 50 anos de idade (G1, G2 e G8), nenhum participante tem menos de 30 anos, um possui entre 30 e 40 anos (G9), dois entre 50 e 60 (G6 e G11) e outro acima de 60 anos (G5), como mostra o Gráfico 1. Essa faixa etária elevada se deve ao fato dos pesquisadores serem líderes de grupos de pesquisa, o que exige uma maior experiência em pesquisa. 


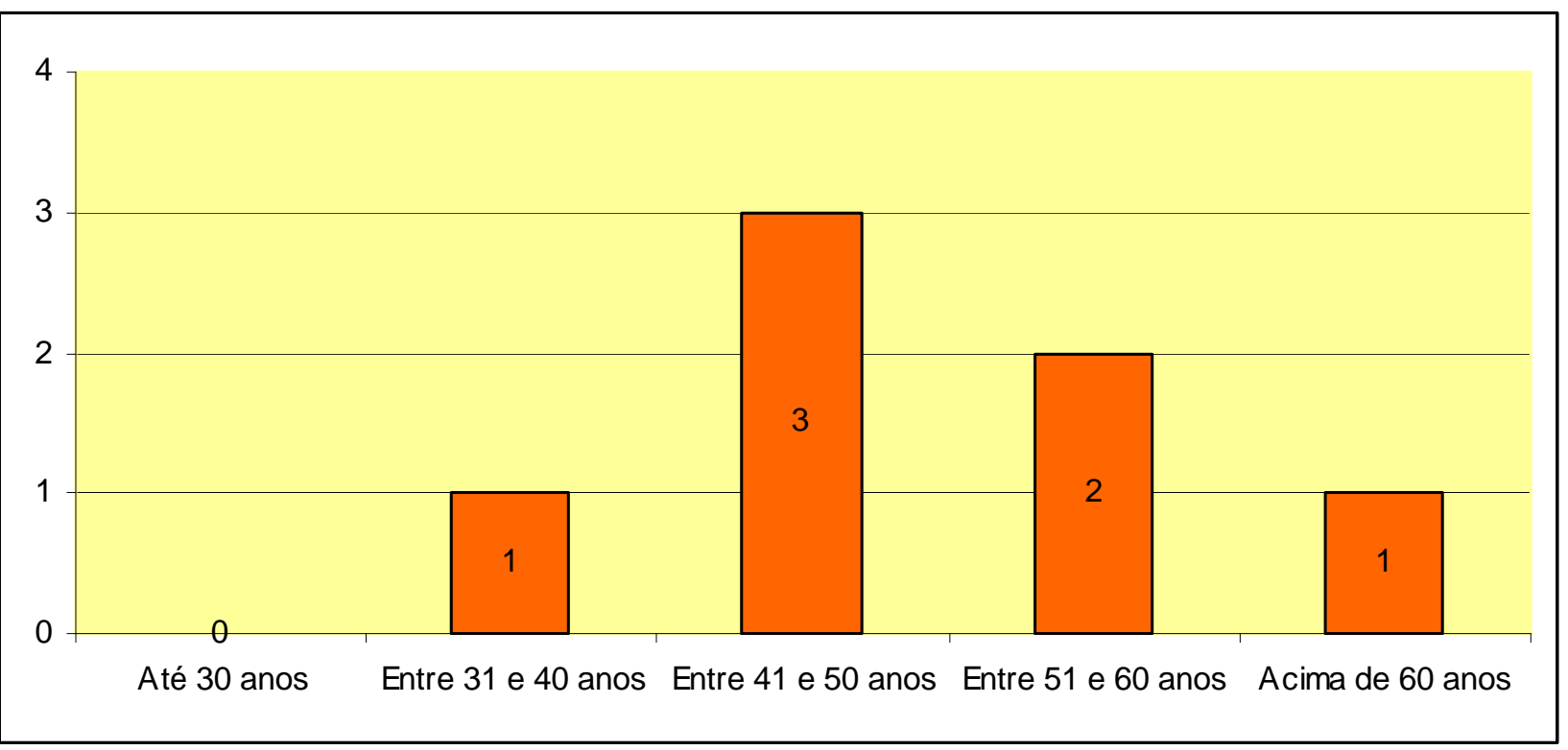

Gráfico 1: Faixa etária

Fonte: Dados da pesquisa

Quanto ao grau de instrução, quatro dos entrevistados possuem doutorado na área em que atuam (G5, G6, G8 e G11) e três possuem pós-doutorado (G1, G2 e G9). É curioso, pois os líderes mais jovens são os que possuem maior formação. Diante disso, percebe-se a importância que se tem dado aos estudos nos dias atuais, o que não ocorria com freqüência antigamente, em que poucas pessoas chegavam ao doutorado.

Convém ressaltar que os líderes do G1, G2, G8, G9 e G11 realizaram pelo menos parte da formação no exterior, seja a graduação, o mestrado, o doutorado, o pós-doutorado ou todas elas. Os líderes do G1 e do G2 são estrangeiros. O alto nível de formação pode ser justificado por parâmetros exigidos para esse tipo de atuação profissional, pela dedicação que estes pesquisadores têm com a carreira acadêmica e, também, pelo total envolvimento com pesquisa científica. Além disso, é preciso conhecimento e experiência para liderar um grupo de pesquisa.

Quanto à participação em grupos de pesquisa, os líderes do G8 e do G11 participam apenas do grupo de pesquisa o qual lideram, enquanto os outros cinco líderes participam também de outros grupos. Destes, as líderes do G2 e do G6 assumem papel de liderança em outros grupos, além dos que são objetos da pesquisa, como consta no Gráfico 2. 


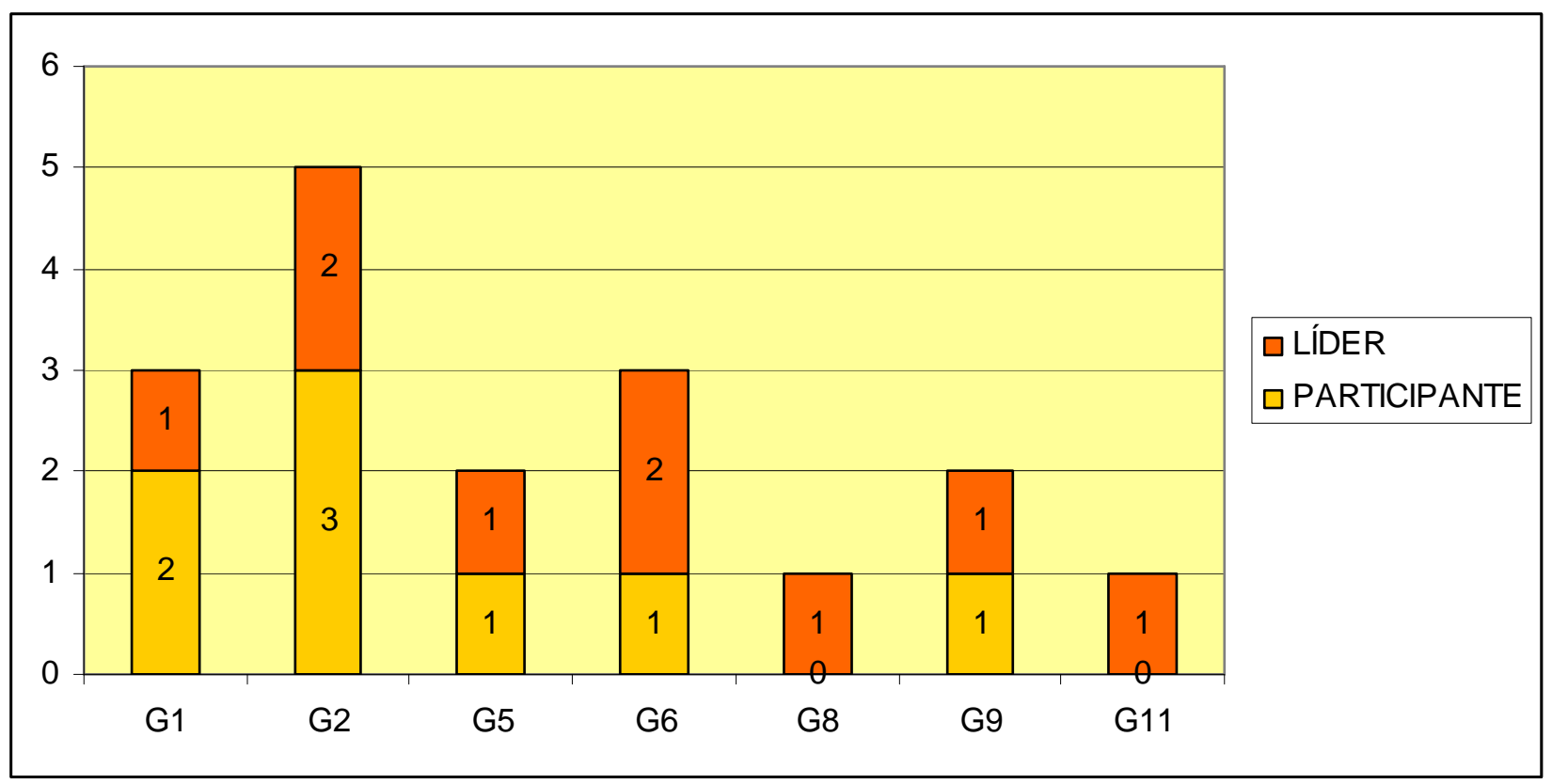

Gráfico 2: Participação em grupos de pesquisa Fonte: Dados da pesquisa

\subsection{Características dos grupos de pesquisa}

Os líderes de cada grupo de pesquisa entrevistado foram questionados quanto ao tempo de formação do grupo, número de integrantes, objetivos do grupo, motivos para a sua formação, como ocorre a seleção para novos membros, quais as competências necessárias para a entrada nos grupos, como é o funcionamento do grupo, atividades desenvolvidas por seus integrantes e como é a produção de conhecimento no grupo.

\subsubsection{Tempo de formação e número de integrantes}

De acordo com os dados obtidos no sítio eletrônico do DGP e com as entrevistas realizadas, o Quadro 1 apresenta algumas características de cada grupo de pesquisa selecionado, relacionadas ao tempo de formação e ao número de integrantes. 


\begin{tabular}{|c|c|c|c|c|c|c|}
\hline \multirow{2}{*}{ GRUPO } & ANO DE & ANO DE & \multicolumn{4}{|c|}{ NÚMERO DE INTEGRANTES } \\
& INÍCIO & FORMALIZAÇÃO & TÉCNICOS & ALUNOS & PROFESSORES & TOTAL \\
\hline G1 & 2004 & 2004 & 1 & 18 & 3 & 22 \\
\hline G2 & 1993 & 1993 & 18 & 60 & 26 & 104 \\
\hline G5 & 1975 & 2006 & 2 & 9 & 11 & 22 \\
\hline G6 & 1989 & 2009 & 0 & 12 & 8 & 20 \\
\hline G8 & 2003 & 2005 & 0 & 6 & 2 & 8 \\
\hline G9 & 2007 & 2007 & 1 & 13 & 11 & 25 \\
\hline G11 & 1997 & 1997 & 2 & 5 & 9 & 16 \\
\hline
\end{tabular}

Quadro 1:Tempo de formação e número de integrantes

Fonte: Dados da pesquisa

Convém ressaltar que os grupos G5 e G6 já existiam antes da exigência da formalização no CNPq, em 1992, e que todos os grupos possuem uma rotatividade grande de participantes, principalmente estudantes.

O G1 está formalizado desde 2004. Entre seus integrantes estão três professores pesquisadores, contando com o coordenador do grupo, dezoito estudantes de graduação, mestrado ou doutorado e um técnico.

O G2 existe há 16 anos e é composto por aproximadamente 26 pesquisadores, 60 alunos (graduação, mestrado ou doutorado) e 18 técnicos. É o grupo desta amostra com o registro mais antigo no CNPq e o que possui o maior número de integrantes.

O G5 trabalha nessa linha de pesquisa há 34 anos. Contudo, apenas em 2006 o grupo foi formalizado. Possui onze pesquisadores, nove estudantes e dois técnicos.

O G6 foi formalizado apenas este ano, porém a sua líder trabalha com essa linha de pesquisa há aproximadamente 20 anos. No DGP consta que o grupo é composto por 20 integrantes, entre professores e estudantes. Porém, na entrevista foi identificado que o grupo possui aproximadamente cinco integrantes e que nenhum deles é estudante de graduação.

O G8 surgiu oficialmente em 2005, mas já existia desde 2003. É o grupo que, de acordo com o DGP, possui o menor número de integrantes: dois professores e seis alunos.

O G9 existe há dois anos. Entre seus componentes estão 11 professores, contando com o líder do grupo, 13 alunos de graduação, mestrado ou doutorado e um técnico.

Para finalizar, o G11 é formado por nove professores, cinco estudantes e dois técnicos e começou a realizar pesquisas em 1997. 


\subsubsection{Objetivos do grupo e área de atuação}

Quando questionados acerca dos objetivos dos grupos de pesquisas dos quais fazem parte, os coordenadores do G1, G2, G5 e G6 apresentaram apenas objetivos ligados às linhas de pesquisa em que estão inseridos.

O objetivo do G1 é identificar organismos patogênicos relacionados ao HIV e tentar descobrir novas abordagens terapêuticas. O G2 tem como objetivos caracterizar os recursos genéticos de animais de fazenda, tanto geneticamente quanto morfologicamente, bem como aplicar o uso desses recursos em sistemas de produção. O principal objetivo do G5 é procurar o melhor tratamento para a leishmaniose. O G6 tem com objetivo analisar, histórica e sociologicamente, as trajetórias da alimentação de determinadas comunidades.

De acordo com a líder do G8, o seu grupo tem "objetivos mais comportamentais dos que de conteúdo". Para ela, o grupo de pesquisa tem o objetivo de compartilhar experiências e abrir espaço para a iniciativa. Os objetivos acadêmicos são: estudar o patrimônio artístico peculiar da cidade de Brasília e explicar o que existe de especial nesse patrimônio.

Para o coordenador do G9, o objetivo consiste em englobar todos os professores que estudam engenharia biomédica em um só grupo. E, por último, o líder do G11 afirma que "o objetivo principal do nosso grupo é envolver pesquisa para ampliar o conhecimento científico" na área de análise de bacias sedimentares.

\subsubsection{Produção de conhecimento}

Ao serem perguntados como se desenvolve o processo de pesquisa e a produção de conhecimento em suas respectivas áreas de atuação, foi identificado que em todos os grupos, a produção do conhecimento parte de uma bibliografia básica, mas se diferencia na metodologia para a coleta e análise de dados devido à área de conhecimento em que estão inseridos.

O G1, pertencente à área de Ciências Biológicas, realiza pesquisa em laboratório. A partir dos resultados alcançados no laboratório, são elaborados artigos e submetidos para publicação em revistas científicas. 
O G2, que pertence à área de Ciências Agrárias, realiza pesquisa em laboratório e, além disso, realiza trabalho prático na Fazenda Água Limpa (FAL), pertencente à UnB. O trabalho prático inclui abate, parto, cirurgia em animais, plantação, construção de cercas, entre outros. De acordo com a líder, os alunos "são fazendeiros, são veterinários, são pesquisadores". A partir daí, os alunos devem sair preparados para exercer a profissão e trabalhos de pesquisa.

No G5, pertencente à área de Ciências da Saúde, os membros trabalham diretamente com atendimento de pessoas infectadas e fazem experimentos com camundongos. Nos dois casos o esquema de tratamento é por meio de um grupocontrole, que recebe as drogas tradicionais ou não recebem nenhuma droga (no caso dos camundongos) e outro grupo que recebe uma droga nova. É feito um comparativo entre a eficácia dos remédios e dos efeitos adversos que podem causar. Portanto, nesse tipo de grupo, o conhecimento é adquirido na prática, a partir da interação com o próprio doente e reflexão quanto aos dados coletados e conhecimento acumulado.

O G6, de Ciências Sociais Aplicadas, produz conhecimento por meio do contato com pessoas e grupos em pesquisas de campo. É feito um comparativo entre cada grupo ou pessoa estudada e, a partir daí, são analisados e discutidos os dados.

Para a produção do conhecimento no G8, pertencente à área de Artes, é necessário que os membros do grupo tenham contato direto com o objeto de estudo e acesso à documentação sobre este objeto.

No G9, grupo da área de Engenharia, os alunos realizam experimentos em laboratório, podendo ser eletrônicos ou em animais. Esses dados são coletados, analisados e, se os resultados forem interessantes, são submetidos à publicação.

No G11, grupo de Ciências Exatas e da Terra, as pesquisas são realizadas em campo, onde são colhidos materiais, como amostras de rocha e do solo, para serem analisados posteriormente.

\begin{tabular}{|c|l|}
\hline GRUPOS & \multicolumn{1}{|c|}{ PRODUÇÃO DE CONHECIMENTO } \\
\hline G1 & Pesquisa em laboratório. \\
\hline G2 & Pesquisa em laboratório e atividades práticas na FAL. \\
\hline G5 & Grupo-controle, tanto em humanos quanto em animais e pesquisa em laboratório. \\
\hline G6 & Contato com pessoas e grupos por meio de pesquisa de campo. \\
\hline G8 & Contato direto com o objeto de estudo. \\
\hline G9 & Experimentos em laboratório, eletrônicos ou em animais. \\
\hline G11 & Pesquisa de campo para coleta de material para análise. \\
\hline
\end{tabular}

Quadro 2: Produção de conhecimento

Fonte: Dados da pesquisa 


\subsubsection{Motivos para a formação}

Como resposta à pergunta: o que motivou a formação do seu grupo de pesquisa, cada grupo de pesquisa teve uma motivação diferente. Entretanto, parte dos grupos de pesquisa estudados já existiam e foram formalizados em virtude de pré-requisitos exigidos por parte do CNPq, para a concessão de financiamentos e para obter um controle maior do que está sendo pesquisado no país.

Para o líder do G1, o que motivou a formação do seu grupo de pesquisa foi a vontade de fazer pesquisa, de transmitir e gerar conhecimento. A líder do G8 também possui o mesmo pensamento: necessidade de compartilhar vivências e experiências, porém complementa que é importante estudar alguma coisa que está no dia-a-dia, que se deve aplicar e processar conhecimento e não apenas acumular o conhecimento adquirido.

A formação do G2 ocorreu em virtude da similaridade de ações de pesquisa que algumas pessoas estavam desenvolvendo. O líder do G9 criou o grupo para que os professores obtivessem um laboratório e pudessem realizar pesquisas. O G6 surgiu devido ao aumento do interesse e da demanda dos alunos pela questão estudada, ou seja, a história da alimentação.

O G5 e o G11 faziam parte de outro grupo de pesquisa. O G5 foi criado por um professor estrangeiro, que realizava pesquisas em países subdesenvolvidos, que detectou o surgimento da leishmaniose no Distrito Federal. Com o falecimento desse professor, o grupo se desintegrou, formando vários grupos menores. A líder atual assumiu a frente de um desses grupos e continuou os estudos na mesma linha de atuação.

Já o líder do G11 percebeu que já tinha potencial para fazer um grupo dentro daquela especialidade: "A gente não seria só uma parte dentro de um grupo maior". Isso aconteceu em virtude do aumento do número de docentes com capacidade de coordenar e orientar alunos de pós-graduação e iniciação científica.

O Quadro 3 resume a motivação para a formação dos sete grupos de pesquisa estudados. 


\begin{tabular}{|c|l|}
\hline GRUPOS & \multicolumn{1}{|c|}{ MOTIVAÇÃO PARA A FORMAÇÃO } \\
\hline G1 & Vontade de realizar pesquisa, transmitir e gerar conhecimento. \\
\hline G2 & Similaridade de ações de pesquisa. \\
\hline G5 & Surgimento da leishmaniose no Distrito Federal. \\
\hline G6 & Aumento do interesse e da demanda dos alunos pela história da alimentação. \\
\hline G8 & $\begin{array}{l}\text { Necessidade de compartilhar vivências e experiências. Estudar algo que está } \\
\text { no dia-a-dia, aplicar e processar conhecimento e não apenas acumulá-lo. }\end{array}$ \\
\hline G9 & Para que os professores tivessem um laboratório para realizarem pesquisas. \\
\hline G11 & $\begin{array}{l}\text { Aumento do número de professores capazes de coordenar e orientar alunos } \\
\text { de pós-graduação e iniciação científica interessados em um mesmo tema. }\end{array}$ \\
\hline
\end{tabular}

Quadro 3: Motivação para a formação

Fonte: Dados da pesquisa

\subsubsection{Seleção de membros}

Com relação as perguntas: como é o processo para o ingresso de novos participantes no grupo e como é feita a seleção dos alunos que participam do grupo, percebeu-se que a seleção de novos membros dos grupos segue critérios diferenciados para estudantes e professores. Geralmente, para o ingresso de novos estudantes, os grupos seguem as normas do Programa Institucional de Bolsas de Iniciação Científica (PIBIC) ou do próprio processo seletivo para a entrada na pósgraduação, podendo haver exceções. Já o ingresso de novos professores ocorre de maneira diferenciada entre os grupos pesquisados.

De acordo com o líder do G1, existe muita procura para a pós-graduação, que está diretamente ligada ao grupo. Para a entrada no grupo, o candidato deve fazer um estágio de aproximadamente um semestre, em que será feito um projeto e começará o estudo e o trabalho sobre o assunto. Esse estágio tem o objetivo de identificar os alunos que realmente têm interesse em realizar pesquisa. Caso haja o interesse, o candidato entra para a pós-graduação e, conseqüentemente, para o grupo. Para o ingresso dos alunos de PIBIC, o líder tenta identificar se o aluno possui um conhecimento prévio sobre o assunto, se realmente tem interesse na pesquisa ou se está apenas em busca da bolsa-auxílio, pois, de acordo com o mesmo, "por uma questão cultural, os objetivos dos alunos sempre são econômicos e financeiros". Por este motivo, o coordenador tem evitado alunos de PIBIC. A forma de ingresso de novos professores no grupo não foi mencionada pelo entrevistado.

Conforme o líder do G2, não está havendo entrada de novos pesquisadores, que seriam os professores, no grupo, pois "é uma área bastante específica, não tem 
muita gente aparecendo". Já o processo seletivo para a entrada de estudantes segue as normas do PIBIC e da pós-graduação. Essa entrada é motivada pela disponibilidade de bolsa-auxílio ou pela exigência de mais pessoas para a realização das pesquisas, devido à elevada quantidade de trabalho.

No G5, a seleção de alunos de graduação é feita por meio do PIBIC, podendo o aluno ser bolsista ou voluntário. Para o mestrado ou doutorado, a entrada se dá a partir das normas da pós-graduação e a pessoa, geralmente, já tem um referencial do grupo ou alguma familiaridade com a doença estudada. Não há um processo seletivo específico para novos pesquisadores, normalmente o ingresso ocorre pela necessidade de conhecimentos específicos em uma determinada área. Esses novos pesquisadores, geralmente, concluíram a graduação na universidade, foram admitidos no Hospital Universitário de Brasília (HUB) ou já sabiam da existência do grupo.

A entrada de membros no G6 ocorre, geralmente, por convite. Já houve caso de candidatos que se interessaram em participar do grupo, mas, após uma apresentação, não foram aceitos. De acordo com o líder, "é sempre uma questão de uma primeira apresentação e, a partir daí, o grupo decide se a pessoa vai entrar ou não". No momento, o grupo não possui nenhum aluno de PIBIC como membro.

Para a líder do G8, "a seleção ocorre no momento em que se assume o compromisso de se orientar um PIBIC". Contudo, a líder prefere alunos conhecidos e realiza uma entrevista informal, para poder ter um primeiro contato e identificar o que o aluno realmente deseja, suas expectativas e experiências significativas dentro da universidade. Para decidir quanto ao ingresso de um aluno, a líder verifica a possibilidade de atendimento das expectativas do aluno, para não gerar frustração.

No G9, assim como no G1, a entrada na pós-graduação já significa a entrada no grupo. Portanto, a entrada desses alunos se dá por meio do edital da pós-graduação, ou seja, análise curricular, carta de referência e análise do préprojeto de pesquisa. Para a entrada de alunos da graduação, geralmente são oferecidas vagas aos melhores alunos das disciplinas ministradas pelos membros do grupo. A entrada de novos professores não foi mencionada.

$E$, por último, no $G 11$, não existe uma forma de seleção para novos professores. De acordo com o líder, 
quer é que haja uma produção científica. A seleção é natural, já é a prova que ele fez para entrar no Instituto. Nós temos que acolher, agregar e fazer com que participem das nossas atividades.

Já os alunos são os professores que selecionam por meio de entrevista, levando em consideração o conhecimento do aluno, o histórico, o Índice de Rendimento Acadêmico (IRA) e o interesse em desenvolver pesquisa.

\begin{tabular}{|c|c|}
\hline GRUPOS & SELEÇÃO DE MEMBROS \\
\hline G1 & $\begin{array}{l}\text { Estudantes de pós graduação: estágio de um semestre (realização de projeto, } \\
\text { trabalho e estudo sobre o assunto) para identificar o interesse do aluno em } \\
\text { pesquisa. } \\
\text { Estudantes de graduação: normas do PIBIC. Conhecimento prévio do assunto e } \\
\text { interesse em pesquisa. O líder evita os alunos de graduação. } \\
\text { Professores: não mencionou. }\end{array}$ \\
\hline G2 & $\begin{array}{l}\text { Estudantes de pós-graduação: segue as normas da pós-graduação. } \\
\text { Estudantes de graduação: segue as normas do PIBIC. } \\
\text { Professores: não tem muitos professores novos na área. }\end{array}$ \\
\hline G5 & $\begin{array}{l}\text { Estudantes de pós-graduação: segue as normas da pós-graduação. } \\
\text { Estudantes de graduação: segue as normas do PIBIC (bolsista ou voluntário) } \\
\text { Professores: pela necessidade de conhecimento na área. }\end{array}$ \\
\hline G6 & $\begin{array}{l}\text { Estudantes de pós-graduação e professores: geralmente por convite } \\
\text { Estudantes de graduação: não tem nenhum no momento. }\end{array}$ \\
\hline G8 & $\begin{array}{l}\text { Estudantes de graduação e pós-graduação: prefere alunos que já conhece, realiza } \\
\text { entrevistas informais, identifica o desejo, expectativas e experiências do aluno. } \\
\text { Professores: não mencionou. }\end{array}$ \\
\hline G9 & $\begin{array}{l}\text { Estudantes de pós-graduação: segue as normas da pós-graduação, edital (análise } \\
\text { curricular, carta de referência e pré-projeto) } \\
\text { Estudantes de graduação: são oferecidas vagas aos melhores alunos de } \\
\text { determinadas matérias. } \\
\text { Professores: não mencionou. }\end{array}$ \\
\hline G11 & $\begin{array}{l}\text { Estudantes de graduação e pós-graduação: os professores que selecionam } \\
\text { (consideram o conhecimento, histórico, IRA e interesse em desenvolver pesquisa). } \\
\text { Professores: não existe uma forma específica de seleção. Basta o professor passar } \\
\text { no processo seletivo para o Instituto de Geologia. }\end{array}$ \\
\hline
\end{tabular}

Quadro 4: Seleção de membros

Fonte: Dados da pesquisa

\subsubsection{Competências necessárias}

O Quadro 5 representa as competências exigidas para a entrada em cada grupo de pesquisa, de acordo com os líderes dos mesmos. Essas respostas foram obtidas com base na pergunta: quais são os pré-requisitos e competências (conhecimentos, habilidades e atitudes) necessários para a participação no grupo?

Desses grupos, apenas o G1, o G8 e o G11 exigiram conhecimentos específicos a respeito da área de atuação. E, mesmo assim, foram exigidos 
conhecimentos básicos superficiais. Os líderes citaram, em sua maioria, comportamentos e atitudes desejados para os membros dos grupos.

A atitude desejada mais mencionada foi o interesse, seja pelo trabalho ou pela pesquisa que está sendo realizada. Inclusive, a líder do G5 afirmou que o interesse pelo trabalho é fator fundamental para a participação no grupo.

\begin{tabular}{|c|c|}
\hline GRUPOS & COMPETÊNCIAS NECESSÁRIAS \\
\hline G1 & $\begin{array}{l}\text { Profissionalismo - ver o grupo como um trabalho e não como um hobby. } \\
\text { Objetivo profissional - ter interesse em pesquisa. } \\
\text { Determinação/vontade - estar disposto a trabalhar e a se sacrificar pelo trabalho. } \\
\text { Conhecimento do assunto - "não precisa ser craque, super gênio" }\end{array}$ \\
\hline G2 & $\begin{array}{l}\text { Trabalho em equipe/ajuda mútua - um membro deve auxiliar o outro. } \\
\text { Interesse pelo trabalho. }\end{array}$ \\
\hline G5 & $\begin{array}{l}\text { Interesse pelo trabalho - fator fundamental. "Muitas vezes ele é até um aluno que não } \\
\text { tem uma média muito grande dentro da própria universidade ou então ele não fez em } \\
\text { uma universidade pública ou ele não tem um referencial tão grande de ser um bom } \\
\text { aluno, mas ele demonstrou interesse, então nós procuramos estimulá-lo". }\end{array}$ \\
\hline G6 & $\begin{array}{l}\text { Experiência em pesquisa - "uma pessoa que já tenha feito algum trabalho de campo, } \\
\text { algum levantamento bibliográfico". } \\
\text { Disponibilidade de tempo - para as reuniões. }\end{array}$ \\
\hline G8 & $\begin{array}{l}\text { Bibliografia básica - vocabulário comum. Por exemplo: entender a diferença entre os } \\
\text { conceitos modernismo, modernidade e moderno. } \\
\text { Domínio da escrita - "não é simplesmente passar em português e redação no } \\
\text { vestibular". } \\
\text { Interesse pelo trabalho - "deve saber que pesquisa não é acúmulo de informação } \\
\text { para ser retransmitida". }\end{array}$ \\
\hline G9 & $\begin{array}{l}\text { Formação - geralmente engenheiro eletricista na área de eletrônica, mas já houve } \\
\text { casos de engenheiros mecânicos, matemáticos, educadores físicos, fisioterapeutas e } \\
\text { etc, por ser uma área multidisciplinar. } \\
\text { Qualidade dos alunos - "acho que a maior dificuldade no momento é encontrar RH de } \\
\text { qualidade, alunos bons. O que acontece é que Brasília é uma cidade cara, então os } \\
\text { alunos bons geralmente tem dificuldade de se manter em Brasília com a bolsa do } \\
\text { CNPq, por exemplo". }\end{array}$ \\
\hline G11 & $\begin{array}{l}\text { Conhecimento na área - ponto principal. O conhecimento exigido depende do projeto } \\
\text { e geralmente é mensurado pelas disciplinas que o aluno cursou. } \\
\text { Interesse pelo trabalho. }\end{array}$ \\
\hline
\end{tabular}

Quadro 5: Competências necessárias

Fonte: Dados da pesquisa

\subsubsection{Funcionamento}

De acordo com as entrevistas realizadas, cada grupo possui uma dinâmica de funcionamento diferente. Os grupos G1, G5, G6 e G8 realizam reuniões mensais, quinzenais ou semanais, o G2, o G9 e o G11 se comunicam apenas por e-mail ou realizam reuniões esporádicas de acordo com a necessidade e o G1, o G5 e o G9 realizam encontros diários nos laboratórios. 
O G1 realiza reuniões semanais onde são feitos seminários em que os alunos apresentam o andamento dos seus projetos. Além disso, os alunos e seus supervisores trabalham no laboratório diariamente, durante o horário comercial, podendo, às vezes, trabalhar à noite e aos finais de semana.

O G2, normalmente, se comunica por e-mail. Contudo, cada professor se reúne com seus orientandos na data e na freqüência que lhes for conveniente. $O$ grupo não se responsabiliza e não interfere nessas reuniões.

Por se tratar de grupo da área de saúde, no G5 a dinâmica de funcionamento é um pouco diferenciada. Além de fazerem pesquisa, os membros do grupo realizam atendimento clínico. O grupo se reúne uma vez por semana no ambulatório, atendendo pacientes. De acordo com a líder do grupo, além de realizar pesquisas e projetos, o grupo tem como foco o ensino, tanto para alunos da graduação, como para alunos da pós-graduação. Os membros também fazem pesquisa em laboratório e, semanalmente, ocorrem reuniões dedicadas aos alunos que estão desenvolvendo projetos, para verificação do cronograma e orientação para as próximas atividades.

O G6 normalmente realiza duas reuniões por mês. Em cada reunião um membro do grupo ou algum convidado realiza uma apresentação acerca do tema ou expõe e discute dados coletados em pesquisa de campo.

No G8 ocorrem reuniões quinzenais em que cada aluno expõe e discute o roteiro do seu projeto. Essas reuniões têm o objetivo de identificar as possibilidades viáveis de ser realizar um projeto, para não gerar frustração entre os membros.

O G9, freqüentemente, se comunica por e-mail. Existem alguns encontros durante o semestre, mas sua freqüência depende da disponibilidade dos professores e dos alunos. Porém, os professores e seus orientandos se encontram diariamente no laboratório. Como no G2, esses encontros independem do grupo de pesquisa.

O G11 não realiza reuniões semanais e sim reuniões esporádicas, de acordo com a necessidade, como, por exemplo, para discutir a participação em congressos. Com os orientandos é feita uma reunião para decidir o cronograma e o plano de atividades que precisam ser desenvolvidas $e$, depois, há apenas 0 acompanhamento.

De acordo com Probst e Büchel (1997 apud BASTOS; GONDIM; LOIOLA, 2004), são necessárias comunicação e integração interpessoal para que a aprendizagem individual atinja o nível coletivo. Diante disso, e da noção de que o 
conhecimento tácito exige interações mais intensas (ANAND; GLICK; MANZ, 2002) entende-se que os grupos de pesquisa que interagem com maior freqüência e que possuem reuniões presenciais estão mais aptos a compartilharem os conhecimentos e experiências aprendidos.

\subsubsection{Atividades desenvolvidas pelos alunos}

Em todos os grupos pesquisados, os alunos realizam projetos individuais sendo orientados por um professor com projeto na mesma linha de pesquisa. Dessa forma, todos os alunos realizam atividades relacionadas à obtenção de conhecimentos para a elaboração desses projetos específicos. Além disso, cada grupo tem uma atividade específica, como será exposto a seguir.

No G1, os alunos fazem leituras sobre o tema, apresentam seminários e realizam o trabalho de pesquisa em laboratório.

No G2, além do projeto específico individual, os alunos desenvolvem todas as atividades referentes à profissão. De acordo com o coordenador, "eles estão inseridos dentro do dia-a-dia no trabalho, então eles são veterinários ou agrônomos. Eles estão dentro de um sistema onde eles têm que aprender".

No G5 cada aluno executa o seu projeto, podendo ser clínico ou em laboratório. Além disso, realizam monitoria nas disciplinas de graduação que a líder leciona: "eles ajudam na disciplina da graduação, dão aulas nas disciplinas da graduação, ajudam a dar aulas práticas para os alunos. A gente procura prepará-los como professores completos".

No G6 os alunos realizam suas pesquisas para as dissertações, apresentando seus dados e resultados durante as reuniões do grupo.

Ao ser perguntado quais atividades são desenvolvidas pelos alunos, a líder do G8 respondeu que os alunos devem "ler, andar, conhecer a biblioteca, ver as coisas, ter contato direto com tudo".

No G9, para obter conhecimentos prévios sobre o tema, os alunos efetuam leitura de artigos. Posteriormente, realizam e analisam experimentos. Em caso de sucesso, submetem os resultados para publicação em periódicos. 
Por último, no G11, as atividades desenvolvidas por alunos de graduação, mestrado e doutorado são diferenciadas. De acordo com o coordenador do grupo,

quando eu tenho um aluno de PIBIC, eu não vou dar para ele uma atividade que eu não sei aonde ele vai chegar. Eu vou dar primeiro uma atividade que eu sei que vai ter princípio, meio e fim e que ele vai chegar lá. Para o aluno de mestrado tem que ter o início, meio e fim para ele chegar também, ele vai ter que superar algumas coisas. Um aluno de doutorado eu acho que é um aluno que tem que se desenvolver um pouco mais sozinho, ele tem que trazer as propostas, discutir, ter iniciativa, desenvolver trabalhos.

\subsection{Aprendizagem e compartilhamento de conhecimento em grupos de pesquisa}

A seguir, serão apresentados como ocorrem os processos de aprendizagem nos diferentes grupos de pesquisa estudados a partir das seguintes categorias: competências desenvolvidas pelo líder, transmissão e compartilhamento de conhecimentos, memória do grupo, resultados alcançados, redes sociais e principais fatores que contribuem para o sucesso, estabelecendo uma relação com 0 conhecimento acumulado sobre o tema e um comparativo entre os grupos.

\subsubsection{Competências desenvolvidas pelo líder}

No Quadro 6 serão relatadas as principais competências desenvolvidas pelos líderes a partir de suas participações nos grupos de pesquisa.

\begin{tabular}{|c|l|}
\hline GRUPOS & \multicolumn{1}{c|}{ COMPETÊNCIAS DESENVOLVIDAS PELOS LíDERES } \\
\hline G1 & $\begin{array}{l}\text { Lidar com seres humanos. } \\
\text { Autocrítica - o que mudar e a maneira de coordenar o grupo. } \\
\text { Relacionamento - a relação pessoal não deve influenciar a profissional }\end{array}$ \\
\hline G2 & $\begin{array}{l}\text { Valorizar as pessoas - todos os trabalhos e todos os tipos de competências são } \\
\text { importantes. } \\
\text { Importância do relacionamento interpessoal - "pessoas conhecem pessoas, que } \\
\text { conhecem pessoas", por esse motivo o grupo hoje se relaciona com pessoas do } \\
\text { Pantanal e da Amazônia Oriental. } \\
\text { Abrir a mente - "é conversando e testando que se abrem novas perspectivas e se } \\
\text { encontram novas soluções" }\end{array}$ \\
\hline G5 & $\begin{array}{l}\text { Convivência em grupo. } \\
\text { Responsabilidades como professor - como lidar com o aluno, como estimulá-lo, como } \\
\text { ser um ponto de referência para ele. } \\
\text { Importância da pesquisa - passou a encarar a pesquisa com mais seriedade. }\end{array}$ \\
\hline G6 & Conhecimento de outras culturas. \\
\hline
\end{tabular}




\begin{tabular}{|c|l|}
\hline & Conhecimentos específicos da área. \\
\hline G8 & Responsabilidade com o compartilhamento de experiências - indicar caminhos \\
\hline G9 & Paciência \\
\hline G11 & $\begin{array}{l}\text { Saber lidar com a diversidade de pensamentos. } \\
\text { Maleabilidade - "as coisas nem sempre são como a gente quer". } \\
\text { Maturidade - "a gente acaba respeitando as idéias de outras pessoas" } \\
\text { Respeito - "tem pessoas que tem mais dom para determinadas atividades do que para } \\
\text { outras. É aprender a ver isso, porque todo mundo tem a sua competência em algum } \\
\text { lugar. Então tem pessoa que não tem determinada competência para fazer determinada } \\
\text { coisa, então se você enxerga isso você não vai brigar com a pessoa para ela fazer } \\
\text { aquela determinada coisa, vamos tentar procurar uma coisa que ela possa fazer. A } \\
\text { gente tem que respeitar os limites das pessoas, o interesse" } \\
\text { Franqueza - na hora de dizer que alguém não vai atingir seu objetivo. }\end{array}$ \\
\hline
\end{tabular}

Quadro 6: Competências desenvolvidas pelos líderes

Fonte: Dados da pesquisa

Os conteúdos aprendidos e competências desenvolvidas dizem respeito, principalmente, à interação com pessoas, modos de comunicação e autoconhecimento, os quais são fundamentais para o trabalho em equipe, pois o pesquisador não trabalha e nem produz sozinho (GATTI, 2005). Para a autora, essa troca de experiências e informações é essencial para a realização de pesquisas e para o avanço do conhecimento.

\subsubsection{Transmissão e compartilhamento de conhecimentos}

Quando questionados acerca de como os resultados e conhecimentos do grupo são transmitidos para os novos membros, todos os líderes, com exceção do líder do G11, responderam que é por meio da leitura de artigos e por meio das publicações.

Esse tipo de conhecimento pode ser classificado como conhecimento explícito ou codificado, que é definido como um conjunto de informações contidas em algum material que pode ser impresso ou apenas lido (MIRANDA, 1999). Esse tipo de conhecimento é facilmente transferido e dispensa interações mais intensas (ANAND; GLICK; MANZ, 2002). Contudo, parte do conhecimento que pode ser compartilhado em um grupo de pesquisa é tácito e sua transferência ocorre apenas por meio da interação humana. Se não ocorre essa interação, provavelmente não ocorre o compartilhamento de todos os conhecimentos.

O líder do G1 ainda mencionou um problema: "as pessoas não ficam. Quando estão prontas vão embora”. De acordo com Renaux et al. (2001 apud LIMA; 
AMARAL, 2008) há perda de competências devido à grande rotatividade nos grupos de pesquisa. No G1, quem detém a maior parte do conhecimento é o líder do grupo. Para ele, "se ficassem uma ou duas pessoas, esse conhecimento era mantido, aí coordenador serviria mais para correr atrás de financiamento". No G1, o conhecimento é compartilhado por meio da leitura de papers, trabalhos, discussões e seminários, mas cada um deve ter determinação e buscar o conhecimento que for necessário.

No G2 e no G8 o compartilhamento dos conhecimentos ocorre por meio de publicações e congressos. Participar de congressos é uma forma de aquisição externa de conhecimento. Realizar atividade de pesquisa é um tipo de aquisição interna de conhecimento (TACLA; FIGUEREDO, 2003 apud LOIOLA; NÉRIS; BASTOS, 2006). A aquisição externa contribui para a aquisição de conhecimentos mais complexos. Enquanto a interna auxilia a aquisição de conhecimentos mais específicos (ANTONELLI, 2002 apud LOIOLA; NÉRIS; BASTOS, 2006).

No G5 os conhecimentos obtidos são divulgados em congressos e revistas científicas. Além disso, há a preocupação de apresentar os resultados ao Ministério da Saúde, com o intuito da aplicação do conhecimento adquirido, ou seja, novos tratamentos para a leishmaniose, em todo o país. No G5 o conhecimento também é compartilhado por meio da interação entre alunos e professores em sala de aula, em que aprendem parte do conhecimento teórico e a aplicação desse conhecimento é feito nas aulas práticas em laboratório. Ou seja, ocorre a aquisição de conhecimento em sala de aula, de modo que esse conhecimento é retido pelo aluno e generalizado quando aplicado no contexto real: o tratamento dos pacientes. De acordo com a líder, as experiências pessoais são compartilhadas pelas interações em sala de aula e nas reuniões do grupo.

A líder do G6 apóia os alunos fornecendo o que já foi produzido e algumas indicações bibliográficas. A participação em congressos também é estimulada: "eu acho que é importante sempre alguns irem. Depois relatam o que aconteceu, como foi, coisas novas que apareceram, contribuições interessantes [...]". Essa é uma forma de manter o grupo todo atualizado, a partir da aquisição externa de conhecimento, por meio de congresso, que depois é socializada entre os membros do grupo.

No G9, o compartilhamento de conhecimentos ocorre por meio de artigos e "através dos professores mais antigos". Geralmente, um professor adquire um 
conhecimento novo, em pós-doutorado ou em visitas a outras universidades, e introduz no grupo. Porém, esse conhecimento só é assimilado por aqueles que

estão interessados naquele aspecto. [...] Geralmente não tem um conhecimento que vai ser útil para todos ao mesmo tempo, mas cada conhecimento dois ou três membros acham interessante e vêem que podem aplicar também na sua pesquisa particular, aí absorvem.

No G11, o compartilhamento de conhecimentos com professores e estudantes é diferente. De acordo com o líder, o professor já tem capacidade de buscar as informações necessárias. Já para os estudantes, tanto de graduação como de pós-graduação, esse compartilhamento de conhecimento é em função do plano de trabalho que o aluno está executando.

[...] Muitas vezes a participação dele não é uma participação que ele vai se interar de todas as atividades do grupo de pesquisa. Ele participa do grupo com aquele trabalho, que é a contribuição dele para o grupo. Isso não significa que o aluno participante tem que estar obrigatoriamente por dentro de todas as atividades do grupo de pesquisa. Logicamente, se ele demonstrar interesse, ele vai chegar lá.

Verificou-se, portanto, que o compartilhamento de conhecimentos se dá, principalmente, a partir da codificação desses conhecimentos, seja em livros, artigos, periódicos, entre outros. Poucos grupos têm a preocupação em compartilhar esses conhecimentos por meio da socialização. Os grupos que mais se destacaram com relação à transmissão de conhecimento tácito foram o G5 e o G9, pertencentes às áreas de Saúde e Engenharia.

O Quadro 7 apresenta de forma resumida as principais especificidades de cada grupo.

\begin{tabular}{|c|c|}
\hline GRUPOS & TRANSMISSÃO E COMPARTILHAMENTO DE CONHECIMENTOS \\
\hline G1 & $\begin{array}{l}\text { Leitura de papers, trabalhos, discussões e seminários, mas cada um deve ter } \\
\text { determinação e buscar o conhecimento que for necessário. O maior problema é que as } \\
\text { pessoas competentes saem do grupo e carregam as competências obtidas. }\end{array}$ \\
\hline G2 & Publicações e congressos \\
\hline G5 & $\begin{array}{l}\text { Participação em congressos e publicação em revistas científicas. Interação entre } \\
\text { alunos e professores em sala de aula e aplicação prática em laboratório. As } \\
\text { experiências pessoais são compartilhadas pelas interações em sala de aula e nas } \\
\text { reuniões do grupo. }\end{array}$ \\
\hline G6 & $\begin{array}{l}\text { Indicações bibliográficas, participação em congressos e, posteriormente, reuniões em } \\
\text { que são discutidos os temas do congresso, suas principais abordagens e novidades } \\
\text { sobre o assunto. }\end{array}$ \\
\hline G8 & Publicações e congressos \\
\hline G9 & $\begin{array}{l}\text { Leitura de artigos. Introdução de novos conhecimentos no grupo a partir da participação } \\
\text { de professores em pós-graduações ou visitas a outras universidades. }\end{array}$ \\
\hline G11 & $\begin{array}{l}\text { Os professores buscam as informações e conhecimentos desejados. Com os } \\
\text { estudantes o conhecimento é compartilhado em função do plano de trabalho que o }\end{array}$ \\
\hline
\end{tabular}


aluno está executando.

Quadro 7: Transmissão e compartilhamento de conhecimentos

Fonte: Dados da pesquisa

\subsubsection{Memória do grupo}

Quanto à memória, os líderes não demonstraram preocupação em manterem organizados os conhecimentos adquiridos e produzidos pelos grupos, de maneira que outras pessoas pudessem ter fácil acesso. Todos os grupos possuem como memória apenas os artigos, dissertações e teses publicados, sendo encontrados por meio de consulta aos Currículos Lattes dos líderes e ao DGP, se estiverem atualizados, ou contato direto com os próprios líderes.

\begin{tabular}{|c|l|}
\hline GRUPOS & \multicolumn{1}{c|}{ MEMÓRIA DO GRUPO } \\
\hline G1 & $\begin{array}{l}\text { Por meio de publicações: artigos científicos, monografias, dissertações e teses. } \\
\text { Pretende informatizar o laboratório. } \\
\text { Possui um sítio eletrônico. }\end{array}$ \\
\hline G2 & $\begin{array}{l}\text { Por meio de publicações: artigos científicos, monografias, dissertações e teses. } \\
\text { Está criando um sítio eletrônico. }\end{array}$ \\
\hline G5 & Por meio de publicações em periódicos, livros e arquivos em computadores. \\
\hline G6 & $\begin{array}{l}\text { Por meio do registro no CNPq, que está desatualizado. } \\
\text { Publicação em uma coluna de um sítio eletrônico - para popularizar o conhecimento } \\
\text { Por meio de publicações: artigos científicos, monografias, dissertações e teses. }\end{array}$ \\
\hline G8 & $\begin{array}{l}\text { Possui um blog em que constam documentos, registros e referências da história do } \\
\text { grupo. }\end{array}$ \\
\hline G9 & Por meio de publicações: artigos científicos, monografias, dissertações e teses. \\
\hline G11 & Por meio dos Currículos Lattes dos pesquisadores. \\
\hline
\end{tabular}

Quadro 8: Memória do grupo

Fonte: Dados da pesquisa

\subsubsection{Resultados alcançados}

Quanto aos resultados alcançados, todos os grupos citaram a publicação de artigos em congressos, periódicos ou revistas, além das monografias, dissertações e teses. Além disso, o G2, o G5 e o G11 obtiveram resultados um pouco mais específicos.

O G1 disse ter alcançado poucos resultados, pois, de acordo com o coordenador, não há interesse do Ministério da Saúde em encontrar novas drogas que combatam a doença, objeto de pesquisa do grupo. Para o mesmo, o objetivo do 
Ministério é quebrar patentes e não criar novas patentes, o que acaba por desmerecer o trabalho que o grupo tenta realizar.

Em contrapartida, o G9 tem gerado algumas patentes e já ganhou visibilidade nacional. Alguns alunos, inclusive, constituíram empresa para disponibilizar no mercado os produtos desenvolvidos a partir dos resultados alcançados no mestrado. Além disso, o líder afirmou que o número de publicações aumentou: "o grupo tem publicado, em média, oito a dez artigos por ano". Isso confirma a hipótese de que a quantidade e a qualidade das pesquisas científicas e de artigos publicados em revistas e congressos aumentam com o trabalho em grupo (ACEDO et al., 2006 apud ODELIUS; SENA, 2009).

O G2, que trabalha com genética de animais, identificou alguns genes, mostrando diferenças genéticas entre algumas raças bovinas. Possui reconhecimento nacional e está desenvolvendo este mesmo estudo no exterior, com o objetivo de identificar as raças bovinas que se adaptam melhor ao clima e à vegetação da área de estudo. O curso de pós-graduação também foi um resultado do grupo de pesquisa, pois, com o grupo de pesquisa, aumentou a demanda de estudantes nessa área.

O G5, a partir do estudo clínico, estabeleceu um esquema terapêutico diferenciado para a leishmaniose e submeteu à Organização Mundial de Saúde (OMS), que adotou este esquema como tratamento da doença estudada. Também testaram novas drogas, que foram eficazes no tratamento da doença, dando um respaldo maior para a OMS e para o Ministério da Saúde.

O G6 está com diversas publicações e estão preparando um grande evento para o próximo ano. O grupo participa de congressos e tem sido bastante convidado para dar palestras.

O G8 participa de congressos nacionais e internacionais na área, participa de eventos, simpósios e possui algumas publicações.

Por último, o G11 adquiriu respeito, interação e igualdade no meio internacional, fazendo, inclusive, publicações em revistas estrangeiras. Além disso, possui diversas publicações de mestrado, doutorado e iniciação científica.

\begin{tabular}{|c|lccc|c|}
\hline GRUPOS & \multicolumn{5}{|c|}{ RESULTADOS ALCANÇADOS } \\
\hline G1 & $\begin{array}{l}\text { Alcançou poucos resultados, pois não há interesse do Ministério da Saúde em } \\
\text { encontrar novas drogas que combatam o HIV. }\end{array}$ \\
\hline G2 & Identificou genes e encontrou diferenças genéticas entre raças bovinas. \\
\hline
\end{tabular}




\begin{tabular}{|c|c|}
\hline & $\begin{array}{l}\text { Reconhecimento nacional e desenvolvimento de estudos no exterior. Criação da pós- } \\
\text { graduação. }\end{array}$ \\
\hline G5 & $\begin{array}{l}\text { Criação de um tratamento diferenciado para a leishmaniose, que foi adotado pela OMS. } \\
\text { Teste de novas drogas que combatam a leishmaniose. }\end{array}$ \\
\hline G6 & Publicacões, convites para palestras e participacão em congressos. \\
\hline G8 & $\begin{array}{l}\text { Participação em congressos nacionais e internacionais e participação em eventos, } \\
\text { simpósios e algumas publicações. }\end{array}$ \\
\hline G9 & $\begin{array}{l}\text { Gerou patentes e ganhou visibilidade nacional. Alguns alunos constituíram empresa } \\
\text { com o objetivo de colocar no mercado os produtos desenvolvidos. }\end{array}$ \\
\hline G11 & $\begin{array}{l}\text { Respeito, interação e igualdade no meio internacional e publicação em revistas } \\
\text { estrangeiras. }\end{array}$ \\
\hline
\end{tabular}

Quadro 9: Resultados alcançados

Fonte: Dados da pesquisa

\subsubsection{Grupos de pesquisa e suas redes sociais}

Ao serem questionados se possuíam interação com outros grupos de pesquisa, da mesma área de conhecimento ou não, grande parte dos líderes respondeu que interage com outros grupos e com outras áreas, por motivos diversos.

No G2 essas interações acontecem para o compartilhamento de informações, experiências e equipamentos. O grupo, da área de Ciências Agrárias, mantém interação com pessoas da Química, para a realização de análises químicas, com professores da Geologia, que possuem equipamentos que fazem análises sofisticadas, da Geografia, Estatística, entre outros. De acordo com a líder, "você sempre tem que conhecer alguém. Você sempre tem que ter quem trabalhe com isso. É uma rede grande de pessoas conhecidas. [...] Não podemos dizer que somos um grupo de pesquisa isolado".

O G5 procura agregar professores de outras áreas a partir da necessidade que tem de estudá-las. Conforme a líder do grupo, "há a necessidade de trabalhar com imunologia, agregamos imunologistas. Há a necessidade de trabalhar com epidemiologia, agregamos epidemiologistas. Então, nós estamos sempre expandindo o grupo com outros professores e alunos". A intenção dessas relações é complementar o estudo. Além disso, o grupo trabalha com a Embrapa, que contribui emprestando equipamentos.

Contudo, a líder do G5 acredita que falta a integração entre as áreas e os setores dentro da própria universidade: "eu sinto falta disso, de conhecer outras áreas que pudessem dar respaldo para o grupo, para que pudéssemos trabalhar de 
forma mais integrada". O líder do G1 concorda com essa observação. Acredita que a universidade deveria obrigar os pesquisadores a terem projetos conjuntos e a dividir espaço físico. A interação do G1 com outros grupos de pesquisa é mínima, para o líder, falta colaboração entre os pesquisadores.

O G6 interage com grupos que complementam seu estudo com perspectivas diferentes. "Uma ajuda a outra, uma articula com a outra".

O G8 possui vínculos institucionais e faz intercâmbio de informações com universidades de outras cidades. Além disso, possui algum contato com um grupo da História, com quem pretende criar um laboratório, a ser utilizado em conjunto.

O G9 possui linhas de pesquisa compartilhadas, compartilha recursos, profissionais e conhecimentos com grupos da própria Engenharia e com grupos do exterior. Para o líder do G11, "a tendência é multidisciplinar, então a gente tem que ter integração".

A interação que estes grupos de pesquisa possuem dentro do próprio grupo e com outros grupos exemplifica o que são redes sociais: conjunto de indivíduos que unem suas idéias e recursos em prol de valores em comum (MARTELETO, 2001).

\begin{tabular}{|c|l|}
\hline GRUPOS & \multicolumn{1}{|c|}{ REDES SOCIAIS } \\
\hline G1 & $\begin{array}{l}\text { Interação mínima com outros grupos, pois falta colaboração entre os } \\
\text { pesquisadores. }\end{array}$ \\
\hline G2 & $\begin{array}{l}\text { Possui interação com pessoas da Química, Geologia, Geografia, Estatística, } \\
\text { entre outras, com o objetivo de compartilhar informações, experiências e } \\
\text { equipamentos. }\end{array}$ \\
\hline G5 & $\begin{array}{l}\text { Possui interação com pesquisadores de outras áreas com o objetivo de } \\
\text { complementar o estudo. Para a líder, falta integração entre as áreas e } \\
\text { setores dentro da UnB. }\end{array}$ \\
\hline G8 & $\begin{array}{l}\text { Interage com grupos que complementam seu estudo com perspectivas } \\
\text { diferentes. }\end{array}$ \\
\hline G9 & $\begin{array}{l}\text { Possui vínculos institucionais e realiza intercâmbio de informações com } \\
\text { universidades de outras cidades. Contato com o grupo de história, pois } \\
\text { deseja compartilhar um laboratório. }\end{array}$ \\
\hline G11 & $\begin{array}{l}\text { Possui linhas de pesquisa compartilhadas, compartilhamento de recursos, } \\
\text { profissionais e conhecimentos com grupos da própria Engenharia e com } \\
\text { grupos do exterior. }\end{array}$ \\
\hline Possui interação com outros grupos, pois a tendência é multidisciplinar. \\
\hline
\end{tabular}

Quadro 10: Redes sociais

Fonte: Dados da pesquisa 


\subsubsection{Principais fatores que contribuem para o sucesso do grupo}

Os entrevistados foram perguntados a respeito dos fatores que contribuem para o sucesso do grupo que lideram. O Quadro 11 resume as principais respostas.

\begin{tabular}{|c|l|}
\hline GRUPOS & \multicolumn{1}{|c|}{ FATORES QUE CONTRIBUEM PARA O SUCESSO DO GRUPO } \\
\hline G1 & Esforço \\
\hline G2 & $\begin{array}{l}\text { Respeito mútuo } \\
\text { Confiança } \\
\text { Interesse comum }\end{array}$ \\
\hline G5 & $\begin{array}{l}\text { Tenacidade } \\
\text { Idealismo } \\
\text { Motivação } \\
\text { Persistência } \\
\text { Foco }\end{array}$ \\
\hline G6 & $\begin{array}{l}\text { Interesse comum } \\
\text { Troca de experiências } \\
\text { Interação }\end{array}$ \\
\hline G8 & $\begin{array}{l}\text { Motivação } \\
\text { Expectativa de construir um perfil profissional diferenciado }\end{array}$ \\
\hline G9 & $\begin{array}{l}\text { Publicação } \\
\text { Financiamento de pesquisa }\end{array}$ \\
\hline G11 & $\begin{array}{l}\text { Integração } \\
\text { Harmonia }\end{array}$ \\
\hline
\end{tabular}

Quadro 11: Fatores que contribuem para o sucesso do grupo

Fonte: Dados da pesquisa

Dentre os fatores mencionados, a resposta da líder do G8 chamou a atenção: expectativa de construir um perfil profissional diferenciado. De acordo com a mesma, muitos alunos procuram participar do PIBIC com o objetivo de atingir um patamar de competências diferenciadas das dos colegas que nunca participaram de um grupo de pesquisa. "Estes alunos buscam um perfil profissional diferenciado, querem fugir do esperado, que é fazer concurso para dar aula". Marafon (2008) já havia chegado a essa conclusão quando afirmou que os grupos de pesquisa podiam se tornar um diferencial na formação de acadêmicos interessados em investigação cientifica, possibilitando a soma de conhecimentos e experiências práticas.

De acordo com Tomael, Alcara e Di Chiara (2005), os fatores confiança e respeito entre os integrantes de uma rede, ou seja, de um grupo, levam ao compartilhamento de informações, que acaba por modificar e ampliar o conhecimento já detido pelo grupo. 


\subsection{Principais resultados da pesquisa}

Por meio dos relatos obtidos dos líderes dos grupos de pesquisa estudados observa-se que, quanto ao funcionamento, os grupos, de maneira geral, têm uma mesma dinâmica: os alunos realizam projetos individuais dentro de uma linha de pesquisa comum. A diferenciação se dá, principalmente, na forma como o conhecimento é produzido e os dados para análise são coletados, pois, dependendo da área e do assunto estudado, o grupo realiza pesquisa em laboratório, entrevistas, pesquisa de campo, coleta de materiais no campo, atendimento a pacientes, atividades na fazenda, entre outras.

Para a participação nos grupos de pesquisa, conclui-se que é necessário o ingressante ter: profissionalismo, objetivo profissional, determinação, interesse pelo trabalho, disponibilidade de tempo, saber trabalhar em equipe e conhecimentos básicos na área. O interesse pelo trabalho foi a competência mais citada e, de acordo com alguns coordenadores, esse é o fator fundamental para a participação nos grupos.

Quanto às competências desenvolvidas pelos líderes, as principais foram: lidar com seres humanos, relacionamento interpessoal, paciência, respeito, convivência em grupo, saber lidar com a diversidade de pensamentos, maleabilidade e maturidade. Percebeu-se, portanto, que a principal competência desenvolvida está relacionada com o trabalho em equipe e com a convivência com outras pessoas, competências fundamentais para um líder.

Com base no estudo realizado, conclui-se que os principais modos de transmissão e compartilhamento de conhecimentos se dá por meio de publicações, artigos científicos, revistas, livros e congressos, sendo esse conhecimentos codificados e facilmente transferíveis. Poucos grupos valorizam as reuniões presenciais com todos os membros, o que acaba prejudicando a interação, a socialização e o conseqüente compartilhamento dos novos conhecimentos adquiridos. Outro fator que dificulta esse compartilhamento e merece destaque é a grande rotatividade dos integrantes dos grupos, mencionado pelo líder do G1. Quando as pessoas deixam o grupo, acabam levando consigo uma parte do conhecimento adquirido. A forma como é mantida a memória do grupo também prejudica a difusão do conhecimento. Os grupos não possuem, de maneira 
organizada e de fácil acesso, todas as publicações e fontes bibliográficas disponíveis.

Dentre os principais resultados alcançados pelos grupos estão: quantidade e qualidade de publicações, participação em congressos, reconhecimento nacional e internacional, criação de patentes, identificação de genes, novo esquema terapêutico, entre outros. Esses resultados acabam por estimular a participação nos grupos e motivam os membros a seguirem suas pesquisas.

Dos grupos pesquisados, a maioria possui interação com outros grupos de pesquisa e com pessoas de outras áreas de conhecimento. Essas interações são importantes para o desenvolvimento dos grupos, pois agregam valor às pesquisas, tornando-as multidisciplinares. Também é importante para os grupos manterem suas redes sociais, para facilitar a troca de conhecimentos, experiências e equipamentos. 


\section{CONCLUSÕES E RECOMENDAÇÕES}

O processo de aprendizagem é um fenômeno complexo e difícil de precisar (LOIOLA; NÉRIS; BASTOS, 2006). Para Bastos, Gondim e Loiola (2004, p. 227), a pesquisa sobre a aprendizagem busca esclarecer a maneira como ocorre a aprendizagem e os modos como as pessoas aprendem.

Sendo a universidade uma das principais fontes formais de conhecimento (RAPINI, 2007), o principal objetivo dessa pesquisa foi descrever os processos de aprendizagem dentro dos grupos de pesquisa e identificar como ocorre a transferência e compartilhamento de conhecimentos dentro desses grupos, pois, de acordo com Lima e Amaral (2008), o principal objetivo de um grupo de pesquisa é gerar conhecimento.

Os objetivos foram alcançados, uma vez que foi possível identificar as principais competências necessárias, as competências desenvolvidas com a participação nos grupos, os modos de compartilhamento de conhecimentos e de manutenção da memória do grupo.

Contudo, verifica-se que, no que concerne às redes sociais, a pesquisa apresentou limitações. Apenas foi possível identificar que os grupos interagem com outros grupos e com pessoas de outras áreas, porém seria interessante traçar o contorno dessas redes, permitindo, dessa maneira, uma análise rica da transferência de conhecimentos.

Outro fator limitante deve-se ao fato dos grupos da área de Ciências Humanas não terem sido estudados, uma vez que os líderes não responderam aos convites. Por este motivo não puderam ser identificadas a forma de funcionamento, as competências necessárias e como é realizada a produção de conhecimento nos grupos pertencentes a essa área.

Em suma, com relação aos objetivos delimitados, considera-se que foram atingidos e que os resultados encontrados contribuirão na construção de conhecimento a respeito de grupos de pesquisa, suas dinâmicas de funcionamento e na maneira como ocorre e é disseminado o conhecimento dentro de cada um deles. 
Convém ressaltar, entretanto, que poderiam ter sido analisados esses mesmos fatores sob a perspectiva dos participantes dos grupos de pesquisa, principalmente alunos, que são quem mais aprendem e que estão diretamente envolvidos nos projetos.

Dessa maneira, propõe-se a realização de estudos que foquem nos membros e ex-membros dos grupos, que podem enriquecer a pesquisa informando o que foi aprendido, como foi aprendido e se esses conhecimentos ainda estão sendo utilizados em outros contextos, no caso dos ex-integrantes. 


\section{REFERÊNCIAS}

ABBAD, G. S.; BORGES-ANDRADE, J. E. Aprendizagem humana em organizações de trabalho. In: ZANELLI, J. C.; BORGES-ANDRADE, J. E.; BASTOS, A. V. B. (Org.). Psicologia, organizações e trabalho no Brasil. Porto Alegre: Artmed, p. 237-275, 2004.

ANAND, V.; GLICK, W. H.; MANZ, C. C. Capital social: explorando a rede de relações da empresa. Revista de Administração de Empresas, v. 42, n. 4, p. 5773, out./dez. 2002.

ANDRÉ, M. E. D. A. Texto, contexto e significados : algumas questões na análise de dados qualitativos. Caderno de pesquisa, v. 45, p. 66-71, mai. 1983. Disponível em < http://www.fcc.org.br/pesquisa/publicacoes/cp/arquivos/599.pdf > Acesso em: 10 out. 2009

BASTOS, A.V.B.; GONDIM, S.; LOIOLA, E. Aprendizagem organizacional versus organizações que aprendem: características e desafios que cercam essas duas abordagens de pesquisa. Revista de Administração da Universidade de São Paulo, v. 39, n. 3, p. 220-230, jul./set. 2004.

BIDO, D. S.; GODOY, A. S.; FERREIRA, J. F; KENSKI, J. M; SCARTEZINI, V. N. Examinando a Relação Entre Aprendizagem Individual, Grupal e Organizacional em uma Instituição Financeira. In: ENCONTRO NACIONAL DA ANPAD, 32., 2008, Rio de Janeiro. Anais... Rio de Janeiro, 2008.

BITENCOURT, C. C.; AZEVEDO, D. O futuro da aprendizagem organizacional: possibilidades e desafios. Revista de Administração de Empresas, v. 46, Edição Especial Minas Gerais, p. 110-112, set. 2006.

BRAZ, L.; MENESES, P. P. M.; SPEZIA, D. S. Classificação, Métodos e Técnicas de Pesquisa. Brasília, 2009. Disponível em:

<http://aprender.unb.br/mod/resource/view.php?id=129555> Acesso em: 28 set. 2009.

CANONGIA, C.; SANTOS, D. M.; SANTOS, M. M.; ZACKIEWICZ, M. Foresight, inteligência competitiva e gestão do conhecimento: instrumentos para a gestão da inovação. Gestão \& Produção, v. 11, n. 2, p. 231-238, mai./ago. 2004.

CARBONE, P. P.; BRANDÃO, H. P.; LEITE, J. B. B.; VILHENA, R. M. P. Gestão por competências e gestão do conhecimento. Rio de Janeiro: Editora FGV, 2009. 
CARVALHO, H. A.; RENAUX, D. P. B.; CARVALHO, H. G. Metodologia para a implantação da gestão da qualidade em centros de pesquisa e desenvolvimento de instituições de ensino. 2001. Disponível em <http://www.pp.ufu.br/Cobenge2001/trabalhos/EQC027.pdf > Acesso em: 8 nov. 2009

CNPq - Diretórios dos Grupos de Pesquisa no Brasil. Disponível em <http://www.cnpq.br/gpesq/apresentacao.htm> Acesso em: 22 set. 2009

FLEURY, M. T. L. Aprendendo a mudar - aprendendo a aprender. Revista de Administração da Universidade de São Paulo, v. 30, n. 3, p. 5-11, jul./set. 1995.

GATTI, B. A. Formação de grupos e redes de intercâmbio em pesquisa educacional: dialogia e qualidade. Revista Brasileira de Educação, n. 30, p. 124-132, set./dez. 2005.

GOMES, A.; ODELIUS, C. C.; ZANCAN, C. Análise de Redes Sociais (ARS) Conceitos, Aplicações e Considerações, 2007. Mimeografado.

GUIMARÃES, T. A. Ambiente de aprendizagem e cultura em organizações: estudo de caso em organização militar. Revista de Administração Universidade de São Paulo, v. 39, n. 3, p. 231-241, jul./set. 2004.

LEMOS, C. Inovação na Era do Conhecimento. Revista Parcerias Estratégicas, n. 8, p. 157-179, mai. 2000.

LIMA, K. K.; AMARAL, D. C. Práticas de gestão do conhecimento em grupos de pesquisa da rede Instituto Fábrica do Milênio. Gestão \& Produção, v. 15, n. 2, p. 291-305, mai./ago. 2008.

LOIOLA, E.; BASTOS, A. V. B. A Produção Acadêmica sobre Aprendizagem Organizacional no Brasil. Revista de Administração Contemporânea, v. 7, n. 3, p. 181-201, jul./set. 2003a.

Ampliando Perspectivas para a Análise da Pesquisa sobre Aprendizagem Organizacional: uma Tréplica. Revista de Administração Contemporânea, v. 7, n. 3, p. 213-219, jul./set. 2003b.

;NÉRIS, J. S.; BASTOS, A. V. B. Aprendizagem em organizações: mecanismos que articulam processos individuais e coletivos. In: BORGESANDRADE, J. E.; ABBAD, G. S.; MOURÃO, L. (Org.). Treinamento, Desenvolvimento e Educação em Organizações e Trabalho: fundamentos para a gestão de pessoas. Porto Alegre: Artmed, p. 114-136, 2006. 
MARAFON, G. J. A importância dos grupos de pesquisa na formação dos profissionais de geografia agrária: a experiência do NEGEF. CAMPO-TERRITÓRIO: revista de geografia agrária, v. 3, n. 5, p. 284-290, fev./2008. Disponível em: <http://www.campoterritorio.ig.ufu.br/viewissue.php?id=5\#Relato_de_experiência> Acesso em: 23 set. 2009.

MARCONI, M. A.; LAKATOS, E. M. Fundamentos de metodologia científica. São Paulo: Atlas, 2007.

MARTELETO, R. M. Análise de redes sociais - aplicação nos estudos de transferência de informação. Ciência da Informação, v. 30, n. 1, p. 71-81, jan./abr. 2001.

MIRANDA, R. C. R. O uso da informação na formulação de ações estratégicas pelas empresas. Ciência da Informação v. 28, n. 3, p. 286-292, set./dez. 1999.

NÉRIS, J. S.; LOIOLA, E. Microprocessos de Aprendizagem em Organizações do Baixo Médio São Francisco. In: ENCONTRO NACIONAL DA ANPAD, 30., 2006, Salvador. Anais... Salvador, 2006.

ODELIUS, C. C.; SENA, A. C. Atuação em grupos de pesquisa: competências e processos de aprendizagem. In: ENCONTRO NACIONAL DA ANPAD, 33., 2009, São Paulo. Anais... São Paulo, 2009.

PILATI, R.; ABBAD, G. Análise Fatorial Confirmatória da Escala de Impacto do Treinamento no Trabalho. Psicologia: Teoria e Pesquisa, v. 21, n. 1, p. 043-051, jan./abr. 2005.

RAPINI, M. S. Interação Universidade-Empresa no Brasil: Evidências do Diretório dos Grupos de Pesquisa do CNPq. Estudos Econômicos, v. 37, n. 1, p. 211-233, jan./mar. 2007.

SANTOS, G. J. A interfuncionalidade entre marketing e gestão de ciência e tecnologia nas empresas. Gestão \& Produção, v. 10, n. 3, p. 329-344, dez. 2003.

SOUZA, Y. S. Organizações de aprendizagem ou aprendizagem organizacional. RAE - Eletrônica, v. 3, n. 1, art. 51, jan./jun. 2004. Disponível em: <http://www.rae.com.br/eletronica/index.cfm?FuseAction=Artigo \&ID $=1812 \& S e c a 0=0$ RGANIZA\&Volume=3\&Numero=1\&Ano=2004> Acesso em: 13 ago 2009.

SOUZA-SILVA, J, C.; SCHOMMER, P. C. A pesquisa em Comunidades de Prática: panorama atual e perspectivas futuras. Organizações \& Sociedade, v. 15, n. 44, p. 105-127, jan./mar. 2008. 
TAKAHASHI, A. R. W.; FISCHER, A. L. Aprendizagem Organizacional como Mudança Cultural e Institucionalização do Conhecimento. In: ENCONTRO

NACIONAL DA ANPAD, 31., 2007, Rio de Janeiro. Anais... Rio de Janeiro, 2007.

TEIXEIRA, E. B.; BEBER, M. C.; GRZYBOVSKI, D. Cooperação e Aprendizagem Organizacional em Organizações Sociais estruturadas em Redes de Cooperação: 0 caso da Rede Integração Social. In: ENCONTRO NACIONAL DA ANPAD, 32., 2008, Rio de Janeiro. Anais... Rio de Janeiro, 2008.

TOMAEL, M. I.; ALCARA, A. R.; DI CHIARA, I. G. Das redes sociais à inovação. Ciência da Informação, Brasília, v. 34, n. 2, p. 93-104, mai./ago. 2005. Disponível em: <http://www.scielo.br/scielo.php?script=sci_arttext\&PID=S010019652005000200010\&lng=en\&nrm=iso>. Acesso em: 17 set. 2009. 


\section{APÊNDICES}

\section{Apêndice A - Convite ao líder para a participação na pesquisa}

Prezado professor (nome do professor),

Fazemos parte do Grupo de Pesquisa: Aprendizagem em Organizações, do Programa de Pós-Graduação em Administração (PPGA) da Universidade de Brasília (UnB), e estamos desenvolvendo pesquisa com o objetivo de descrever os processos de aprendizagem, compartilhamento de conhecimento e relações em rede em grupos de pesquisa da UnB.

Gostaríamos de contar com a sua participação nessa pesquisa e, para tal, solicitamos indicar dias e horários de sua preferência para uma entrevista a ser realizada em seu ambiente de trabalho. A entrevista tem duração aproximada de 30 minutos.

Agradecemos desde já sua atenção e aguardamos resposta.

Os dados para contato são:

Catarina Cecília Odelius - codelius@unb.br, telefone 3307-2342 r. 221 ou por celular: 9976-5367

Integram o grupo de pesquisa professores, alunos de graduação e de pósgraduação, entre os quais estão participando do desenvolvimento desta pesquisa:

Prof. Dra. Catarina Cecília Odelius

Prof. Dra. Gardênia Abbad

Prof. Dr. Tomás de Aquino Guimarães

André Sena

Andrea Togo Mazzei

Camila Escobar

Caroline Viana

Laline Monteiro 
Pedro Resende

Rafael Ono

Tamísia Cristofane Novaes dos Santos

Tatiana Leão Freitas 


\section{Apêndice B - Roteiro semi-estruturado de entrevista}

Prezado Senhor(a),

Nós somos do Programa de Pós-graduação da Universidade de Brasília e estamos realizando uma pesquisa com a finalidade de descrever os processos de aprendizagem, compartilhamento de conhecimento e relações em rede em grupos de pesquisa da UnB. Seu nome foi escolhido por ser coordenador de grupo de pesquisa e por ter sido identificado como uma pessoa que poderia prestar informações e emitir opiniões relevantes a respeito desses temas nesse ambiente específico.

Os dados coletados terão finalidade acadêmica e serão tratados de forma agregada, mantendo-se o anonimato de pessoas e equipes consultadas. Ou seja, seu nome não será mencionado nos relatórios e artigos originários da pesquisa.

Não existem respostas certas ou erradas. O que importa é a percepção de cada entrevistado a respeito do que será perguntado.

Considerando a facilidade para recuperação das informações, solicitamos sua permissão para gravar a entrevista. Isso facilitará sobremaneira a entrevista e o aproveitamento das informações dadas por você.

\section{Questões:}

1. Quais são os objetivos do grupo?

2. Como se desenvolve o processo de pesquisa e a produção de conhecimento na sua área de atuação?

3. O que motivou a formação do grupo?

4. Descreva o processo de surgimento, desenvolvimento e funcionamento do grupo (Como e quando, surgiu; estágios de desenvolvimento; dinâmica de funcionamento: frequência de funcionamento, divisão de trabalho, tomada de decisão, modo de controle e de acompanhamento de atividades, etc.).

5. Quais fatores contribuíram para o desenvolvimento e consolidação do grupo? 
6. Como é o processo para o ingresso de novos participantes no grupo? Como é feita a seleção de alunos que participam do grupo?

7. Quais são os pré-requisitos e competências (conhecimentos, habilidades e atitudes) necessários para a participação no grupo?

8. Quais são as principais dificuldades (internas e externas ao grupo) enfrentadas ao longo da existência do grupo?

9. Que aspectos/características você considera que contribuíram positivamente para os resultados alcançados pelo grupo?

10.O grupo tem interação com outras áreas de conhecimento e/ou grupos de pesquisa? Quais e com que intenção?

11. As características de outros grupos de pesquisa, que atuam na mesma área que a deste grupo, são semelhantes a este? Se não, quais são as diferenças?

12. Qual o apoio dado pela UnB aos projetos do grupo ao longo do tempo?

13. Qual o apoio dado pelos órgãos de fomento aos projetos do grupo ao longo do tempo?

14. Que condições ambientais (ambiente e espaço físico) e materiais (equipamentos, laboratórios, etc) estão disponíveis?

15. Que resultados o grupo tem alcançado ao longo do tempo?

(além das monografias, IC, dissertações, teses, artigos, participação em congressos, pois acredito que estes podem ser verificados a partir do currículo Lattes do Prof. Coordenador)(verificar se o coordenador do grupo está com o currículo atualizado)

16. Como os resultados alcançados são retidos/perpetuados no grupo e como é mantida a memória do grupo?

17. Como as pessoas que ingressam no grupo têm acesso aos resultados do grupo, ou seja, como ocorre a transmissão de conhecimentos no grupo?

18. Que mudanças ocorreram em seu repertório de conhecimentos, habilidades, atitudes e valores a partir da participação no grupo de pesquisa?

19. Como essas mudanças ocorreram? 
20. Que atividades os alunos desenvolvem no grupo de pesquisa?

21. Você poderia fornecer o nome e contatos de participantes do grupo (atuais e exintegrantes)?

\section{DADOS DEMOGRÁFICOS}

1- Estamos chegando ao final da entrevista. Fique à vontade para realizar comentários adicionais e descrever fatos relacionados com a pesquisa que não tenham sido abordados.

2- Para podermos caracterizar os participantes da pesquisa, gostaríamos de ter algumas informações a seu respeito: formação, atuação profissional, tempo de experiência em pesquisa e idade. 